\title{
X-ray Photoelectron Spectroscopy of Select Multi-layered Transition Metal Carbides (MXenes)
}

\author{
Joseph Halim ${ }^{1,2,3}$, Kevin M. Cook ${ }^{4}$, Michael Naguib ${ }^{5}$, Per Eklund ${ }^{3}$, Yury Gogotsi ${ }^{1,2}$, \\ Johanna Rosen ${ }^{3}$, and Michel W. Barsoum ${ }^{1,3}$ \\ ${ }^{1}$ Department of Materials Science \& Engineering, Drexel University, Philadelphia, PA 19104, \\ USA. \\ ${ }^{2}$ A.J. Drexel Nanomaterials Institute, Drexel University, Philadelphia, PA 19104, USA. \\ ${ }^{3}$ Thin Film Physics Division, Department of Physics, Chemistry and Biology (IFM), Linköping \\ University, SE-583 31 Linköping, Sweden. \\ ${ }^{4}$ Materials Engineering Division, Naval Air Systems Command, Patuxent River, MD 20670, \\ USA. \\ ${ }^{5}$ Materials Science and Technology Division, Oak Ridge National Laboratory, Oak Ridge, TN, \\ 37831, USA. \\ *Corresponding Author \\ E-mail: kevin.m.cook1@navy.mil
}

\begin{abstract}
In this work, a detailed high resolution X-ray photoelectron spectroscopy (XPS) analysis is presented for select MXenes - a recently discovered family of two-dimensional (2D) carbides and carbonitrides. Given their 2D nature, understanding their surface chemistry is paramount. Herein we identify and quantify the surface groups present before, and after, sputter-cleaning as well as freshly prepared vs. aged multilayered cold pressed discs. The nominal compositions of the MXenes studied here are $\mathrm{Ti}_{3} \mathrm{C}_{2} \mathrm{~T}_{\mathrm{x}}, \mathrm{Ti}_{2} \mathrm{CT}_{\mathrm{x}}$, $\mathrm{Ti}_{3} \mathrm{CNT}_{\mathrm{x}}, \mathrm{Nb}_{2} \mathrm{CT}_{\mathrm{x}}$ and $\mathrm{Nb}_{4} \mathrm{C}_{3} \mathrm{~T}_{\mathrm{x}}$, where $\mathrm{T}$ represents surface groups that this work attempts to quantify. In all the cases, the presence of three surface terminations, $-\mathrm{O},-\mathrm{OH}$ and $-\mathrm{F}$, in addition to $\mathrm{OH}$-terminations relatively strongly bonded to $\mathrm{H}_{2} \mathrm{O}$ molecules, was confirmed. From XPS peak fits, it was possible to establish the the average sum of the negative charges of the terminations for the MXenes. Based on this work, it is now possible to quantify the nature of the surface terminations. This information can, in turn, be used to better design and tailor these novel 2D materials for various applications.
\end{abstract}

Online supplementary data available from

Keywords: MXene, XPS, metal carbides.

(C) 2015. This manuscript version is made available under the Elsevier user license 


\section{Introduction}

Two-dimensional (2D) materials have become a major focus of the scientific community due to an unprecedented combination of properties and behaviors that result from their reduced dimensionality. For example, single-layer graphene - the most explored 2D material - was shown to have high conductivity at room temperature, while transmitting $97.7 \%$ of visible light.[1-3] In addition to graphene, other 2D materials have been reported, such as hexagonal boron nitride (BN),[4] transition metal dichalcogenides (TMD),[5] such as $\mathrm{MoS}_{2},[6,7]$ and metal oxides and hydroxides.[8] Most 2D solids are typically strongly bonded within atomic sheets that, in turn, are held together in stacks by weak inter-layer forces. As may be expected, the latter allow for the intercalation of molecules between the layers, as well as, the delamination, or separation of the layers into individual flakes.[9]

By definition, both stacked 2D layers and individual 2D flakes are almost entirely comprised of surface. As such, their surface chemistries have a critical influence on their properties and characteristics. For example, hydrophobic graphene can be rendered hydrophilic by oxidizing it to form graphene oxide.[10] The determination of the surface chemistry is therefore an integral component in the characterization and understanding of 2D materials.[11-16]

In 2011, a large new family of 2D materials - layered transition metal carbides and carbonitrides, we labelled MXenes - was discovered.[17] These materials are produced from layered ternary carbides and nitrides known as the $\mathrm{M}_{n+1} \mathrm{AX}$, or MAX, phases,[18] which, in turn, are a large (70+) group of layered hexagonal compounds, where $\mathrm{M}$ is an early transition metal, $\mathrm{A}$ is an A-group element (mostly groups 13 and 14), $\mathrm{X}$ is $\mathrm{C}$ or/and $\mathrm{N}$ and $\mathrm{n}$ is 1 to 3 . To form the corresponding MXene, the A-layers are selectively etched using hydrofluoric acid, HF, or fluoride salts and inorganic acids, such as hydrochloric acid, $\mathrm{HCl} .[19]$ When the Al-layers are etched, they are replaced by surface terminations, such as $-\mathrm{O},-\mathrm{OH}$, and $-F,[20-22]$ resulting in weakly bound stacks of 2D sheets with a $M_{n+1} X_{n} T_{x}$ composition,[23] where $T_{x}$ stands for surface termination.[20-22] To date, the following MXenes have been reported: $\mathrm{Ti}_{3} \mathrm{C}_{2} \mathrm{~T}_{\mathrm{x}}$, 
$\mathrm{Ti}_{2} \mathrm{CT}_{\mathrm{x}}, \mathrm{Nb}_{2} \mathrm{CT}_{\mathrm{x}}, \mathrm{V}_{2} \mathrm{CT}_{\mathrm{x}},\left(\mathrm{Ti}_{0.5}, \mathrm{Nb}_{0.5}\right)_{2} \mathrm{CT}_{\mathrm{x}},\left(\mathrm{V}_{0.5}, \mathrm{Cr}_{0.5}\right)_{3} \mathrm{C}_{2} \mathrm{~T}_{\mathrm{x}}, \mathrm{Ti}_{3} \mathrm{CNT}_{\mathrm{x}}, \mathrm{Ta}_{4} \mathrm{C}_{3} \mathrm{~T}_{\mathrm{x}}, \mathrm{Nb}_{4} \mathrm{C}_{3} \mathrm{~T}_{\mathrm{x}}, \mathrm{Mo}_{2} \mathrm{TiC}_{2} \mathrm{~T}_{\mathrm{x}}$, and

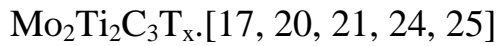

Studies on these materials have included their possible use in energy storage systems, such as lithium ion batteries,[21, 26-28] lithium ion capacitors,[29] aqueous pseudocapacitors,[19, 30] and transparent conductive films.[22] We have also shown that it is possible to intercalate various small organic molecules between the layers.[27] Very recently, we also demonstrated that $\mathrm{Ti}_{3} \mathrm{C}_{2} \mathrm{~T}_{\mathrm{x}}$ not only adsorbed select organic molecules, but may also lead to their photocatalytic decomposition in aqueous environment.[31] The same compound also can be used for various applications from removing $\mathrm{Pb}$ from water to supporting catalysts. $[32,33] \mathrm{The} \mathrm{Ti}_{3} \mathrm{C}_{2} \mathrm{~T}_{\mathrm{x}}$ produced using a mixture of $\mathrm{LiF}$ and $\mathrm{HCl}$ has clay-like properties, and swelled in volume when hydrated. When used as an electrode in a supercapacitor, volumetric capacitance of the order of $900 \mathrm{~F} / \mathrm{cm}^{3}$ was measured for this material, while a volumetric capacitance of about $530 \mathrm{~F} / \mathrm{cm}^{3}$ was measured when the material was used in flexible nanocomposite polymer films.[19, 34] Furthermore, exfoliated MXene particles were shown to delaminate and form a suspension in water after intercalation with several compounds, such as tetrabutylammonium hydroxide and isopropylamine.[35, 36] Common to all of these applications is a need for proper detection and understanding of the functional surface groups present, as they in many cases, largely determine performance.

Given the crucial and vital importance of surface chemistry on MXene properties and applications, it is somewhat surprising that, to date, these surfaces have not been systematically characterized. This paper is a first serious attempt to do so. Herein, we carefully study the surface chemistries of five different MXenes by XPS; the ultimate goal being the building a library of data that can be used to further understand these intriguing materials. XPS is an excellent tool for such studies since it can be used to determine the surface chemical compositions and the chemical states of the various species. By their very nature, non-oxide 2D materials, such as silicene, germanene, phosphorene,[37] and transition metal 
dichalcogenides,[38] are prone to oxidation. The same is true for MXenes such as $\mathrm{Ti}_{3} \mathrm{C}_{2} \mathrm{~T}_{\mathrm{x}}$ and $\mathrm{Ti}_{2} \mathrm{CT}_{\mathrm{x}} \cdot[39-42]$ It follows that an important aim of this work was to probe the oxidation products of the various MXene chemistries. To that effect, we used XPS to examine all the Ti-containing MXenes both directly after synthesis, and after samples were stored in air, for about 12 months. We henceforth refer to the fresh MXene samples as "as-prepared," or "ap- $\mathrm{Ti}_{3} \mathrm{C}_{2} \mathrm{~T}_{\mathrm{x}}$," for example. We refer to the stored samples as "aged," or "ag- $\mathrm{Ti}_{3} \mathrm{C}_{2} \mathrm{~T}_{\mathrm{x}}$," for example.

A comparison of the XPS spectra of as-prepared MXene samples and those stored in air, provides valuable information concerning their propensity to oxidation. The results presented herein show that, despite being stored in air for 12 months, flakes of the Ti-based compositions, did not appear - aside from a shallow ( 10 to $50 \mathrm{~nm}$ ) oxidized outer layer - to be unduly oxidized. The pressed $\mathrm{Nb}_{2} \mathrm{CT}_{\mathrm{x}}$ and $\mathrm{Nb}_{4} \mathrm{C}_{3} \mathrm{~T}_{\mathrm{x}}$ discs were also analyzed both directly after synthesis, and after storing in air. In this case, the samples were stored for about a month before making the measurements. Given the different aging times, between the Ti- and $\mathrm{Nb}$-containing materials we cannot draw any conclusions as to which is more susceptible to oxidation. The information obtained, however is still valuable since information on changes in oxidation species will be obtained nonetheless.

In previous work, the surfaces of $\mathrm{Ti}_{3} \mathrm{C}_{2} \mathrm{~T}_{\mathrm{x}}, \mathrm{Nb}_{2} \mathrm{CT}_{\mathrm{x}}$ and $\mathrm{V}_{2} \mathrm{CT}_{\mathrm{x}}$ were analyzed by XPS $[17,21]$ in order to better understand the role of surface terminations and intercalants on energy storage systems,[27] dye adsorption,[31] and transparent conductive thin films.[22] In this work, we report on more systematic measurements on $\mathrm{Ti}_{3} \mathrm{C}_{2} \mathrm{~T}_{\mathrm{x}}$ and $\mathrm{Nb}_{2} \mathrm{CT}_{\mathrm{x}}$, and extend them to $\mathrm{Ti}_{2} \mathrm{CT}_{\mathrm{x}}, \mathrm{Ti}_{3} \mathrm{CNT}_{\mathrm{x}}$ and $\mathrm{Nb}_{4} \mathrm{C}_{3} \mathrm{~T}_{\mathrm{x}}$.

\section{Material and Methods}

Sample synthesis details can be found in the supplementary materials section S1 along with other information on experimental details and additional data. 


\subsection{X-ray Photoelectron Spectroscopy Analysis}

XPS was performed using a surface analysis system (Kratos AXIS Ultra ${ }^{\text {DLD }}$, Manchester, U.K.) using monochromatic $\mathrm{Al}-\mathrm{K}_{\alpha}(1486.6 \mathrm{eV})$ radiation for all the samples, except for the ap- $\mathrm{Ti}_{3} \mathrm{C}_{2} \mathrm{~T}_{\mathrm{x}}(\mathrm{See}$ supplementary materials section S4 for details). The cold-pressed samples were mounted on double-sided tape and grounded to the sample stage with copper contacts. The X-ray beam irradiated the surface of the samples at an angle of $45^{\circ}$, with respect to the surface and provided an X-ray spot size of $300 \times 800 \mu \mathrm{m}$. The electron energy analyzer accepted the photoelectrons perpendicular to the sample surface with an acceptance angle of $\pm 15^{\circ}$. Charge neutralization was performed using a co-axial, low energy $(\sim 0.1 \mathrm{eV})$ electron flood source to avoid shifts in the recorded binding energy, BE. XPS spectra were recorded for F 1s, O 1s, C 1s, $\mathrm{Al} 2 \mathrm{p}$, Ti 2p, and $\mathrm{Nb} 3 \mathrm{~d}$, as well as, the $\mathrm{N} 1 \mathrm{~s}$ for the $\mathrm{Ti}_{3} \mathrm{CNT}_{\mathrm{x}}$ composition. The analyzer pass energy used for all of the regions was $20 \mathrm{eV}$ with a step size of $0.1 \mathrm{eV}$, giving an overall energy resolution better than $0.5 \mathrm{eV}$. The $\mathrm{BE}$ scale of all XPS spectra was referenced to the Fermi-edge $\left(\mathrm{E}_{\mathrm{F}}\right)$, which was set to a BE of zero $\mathrm{eV}$. Normalization of all spectra was performed at the background on the low-BE side of the main peak/peaks.

The quantification, using the obtained core-level intensities, was carried out using CasaXPS Version 2.3.16 RP 1.6. Peak fitting of core-level spectra was performed using IGOR Pro, Version 6.22A. Prior to peak fitting, the background contributions were subtracted using a Shirley function. For all $2 \mathrm{p}_{3 / 2}$ and $2 \mathrm{p}_{1 / 2}$ components and $3 \mathrm{~d}_{5 / 2}$ and $3 \mathrm{~d}_{3 / 2}$ components, the intensity ratios of the peaks were constrained to be $2: 1$ and 3:2, respectively. A detailed description of the curve fitting process can be found in Supplementary Materials, S4, including information regarding the choice of lineshapes and constraints used to quantify the spectra.

The first step in this study was to establish the chemical nature of these compounds before, and after, $\mathrm{Ar}^{+}$sputtering for $600 \mathrm{~s}$ using a $4 \mathrm{keV} \mathrm{Ar}^{+}$beam raster of $2 \times 2 \mathrm{~mm}^{2}$ over the probed area. Since all samples were in the form of compressed powder discs, comprised of 2D-flakes with high surface areas 
and varied contours, they presented a challenge. However, obtaining spectra before sputter-cleaning allowed for the characterization of the outermost layers of these pressed discs. By their very nature, the un-sputtered surfaces inherently contain a much larger amount of contamination, from ambient oxygen and/or as a result of processing. Nevertheless, such an analysis is crucial for applications that are sensitive to the identity of species in the outermost layers such as photocatalysis. As noted above they also shed critically important light on the stability of these compounds vis-à-vis oxidation. We note in passing that the long time between processing and analysis was in part to understand the stability of the MXene flakes to long-term oxidation.

As will become evident shortly, these systems are non-trivial to characterize, since a relatively large number of surface terminations exist. To render the discussion more transparent, henceforth, each type of termination will be depicted by Roman numerals, as shown in Figure 1 and Table 1. In Figure 1, oxygen atoms are colored red, fluorine blue, hydrogen white and the $\mathrm{M}$ atoms - Ti and $\mathrm{Nb}$ - yellow. Table 1 summarizes the moieties assumed in the MXenes and their peak positions. When taken from the literature, the references are cited.

In reference to Figure 1, the following is how they are defined:

i) Moiety I (labeled I in Figure 1) refers to $\mathrm{M}$ atoms bonded to $\mathrm{C}$ atoms and one oxygen atom, e.g. $\mathrm{Ti}_{3} \mathrm{C}_{2} \mathrm{O}_{\mathrm{x}}$ or $\mathrm{Nb}_{2} \mathrm{CO}_{\mathrm{x}}$.

ii) Moiety II refers to $\mathrm{M}$ atoms bonded to $\mathrm{C}$ atoms and an $\mathrm{OH}$ group, e.g. $\mathrm{Ti}_{3} \mathrm{C}_{2}(\mathrm{OH})_{\mathrm{x}}$ or $\mathrm{Nb}_{2} \mathrm{C}(\mathrm{OH})_{\mathrm{x}}$

iii) Moiety III refers to $\mathrm{M}$ atoms bonded to $\mathrm{C}$ and $\mathrm{F}$ atoms, e.g. $\mathrm{Ti}_{3} \mathrm{C}_{2} \mathrm{~F}_{\mathrm{x}}$ or $\mathrm{Nb}_{2} \mathrm{CF}_{\mathrm{x}}$.

iv) Moiety IV refers to $\mathrm{M}$ atoms bonded to $\mathrm{OH}$-terminations that in turn are relatively strongly physisorbed to water molecules forming $\mathrm{OH}-\mathrm{H}_{2} \mathrm{O}$ complexes (shown as moiety IV in Figure 1), viz. $\mathrm{Ti}_{3} \mathrm{C}_{2} \mathrm{OH}-\mathrm{H}_{2} \mathrm{O}$.[43] These will be henceforth be referred to as $\mathrm{H}_{2} \mathrm{O}_{\text {ads }}$. 

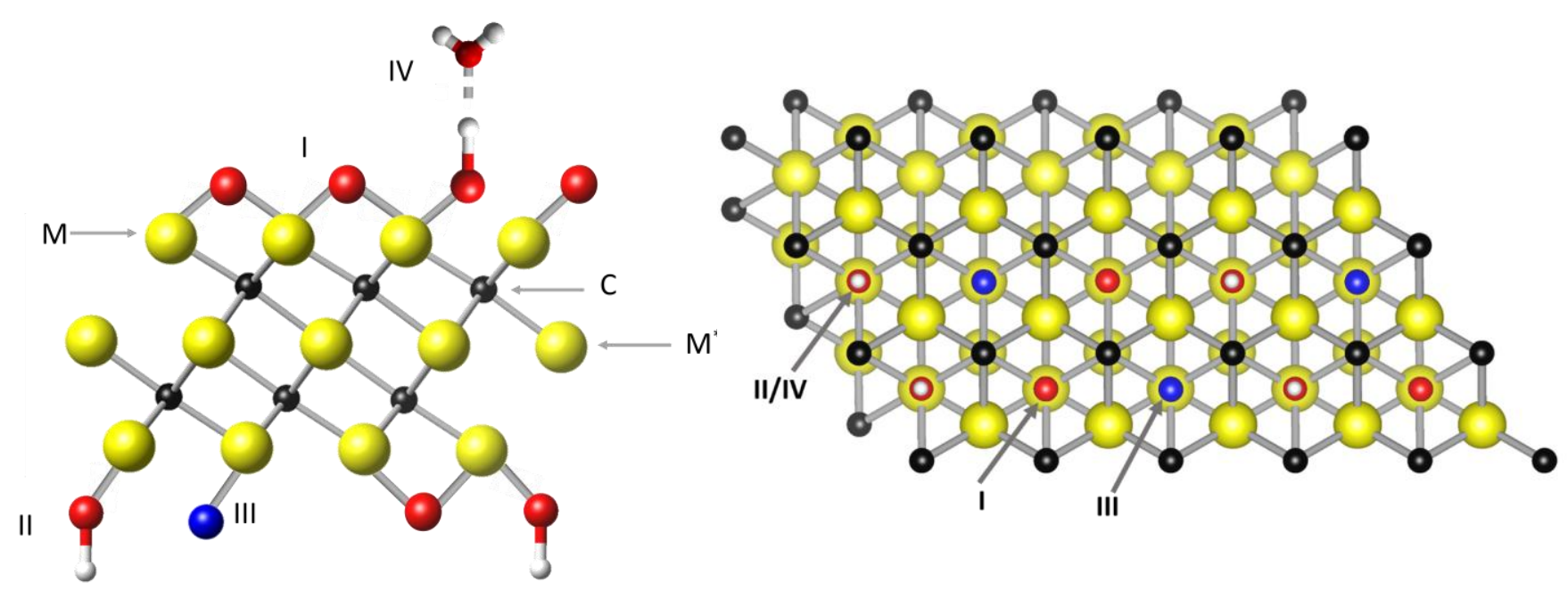

Figure 1. Side (a) and Top (b) view schematics of a $M_{3} X_{2} T_{x}$ structure showing various $M$ atoms and their terminations. I refers to a $\mathrm{M}$ atom bonded to an $\mathrm{O}$ atom, i.e. an oxo group; II to $\mathrm{OH}$; III, to a $\mathrm{M}$ atom directly bonded to a F-atom; IV, to an $\mathrm{M}$ atom bonded to $\mathrm{OH}$, that, in turn, is strongly bonded to a $\mathrm{H}_{2} \mathrm{O}$ molecule. In this schematic, $\mathrm{M}$ atoms are colored yellow, $\mathrm{X}$, black, $\mathrm{O}$, red, $\mathrm{H}$ white and $\mathrm{F}$, blue (not to scale). $\mathrm{M}$ atoms only bonded to $\mathrm{C}$ atoms are designated, $\mathbf{M}^{*}$.

Table 1. Summary of moieties assumed to exist in MXenes and their characteristic energies. Roman numerals refer to the various moieties shown in Figure 1.

\begin{tabular}{|c|c|c|c|}
\hline Moiety & Species & Binding energy $[\mathrm{eV}]$ & Ref. \\
\hline \multirow{2}{*}{ I } & $\mathrm{C}-\mathrm{Ti}^{-} \mathrm{O}_{\mathrm{x}}$ & 531.3 (O 1s region) & {$[43]$} \\
\hline & $\mathrm{C}-\mathrm{Nb}-\mathrm{O}_{\mathrm{x}}$ & 531.0 (O 1s region) & This work \\
\hline \multirow{2}{*}{ II } & $\mathrm{C}-\mathrm{Ti}-(\mathrm{OH})_{\mathrm{x}}$ & 531.7 (O 1s region) & {$[43]$} \\
\hline & $\mathrm{C}-\mathrm{Nb}-(\mathrm{OH})_{\mathrm{x}}$ & $531.6(\mathrm{O}$ 1s region $)$ & This work \\
\hline \multirow{5}{*}{ III } & $\mathrm{C}-\mathrm{Ti}-\mathrm{F}_{\mathrm{x}}$ & 685.2 (F 1s region) & {$[44]$} \\
\hline & $\mathrm{C}-\mathrm{Nb}-\mathrm{F}_{\mathrm{x}}$ & 685.3 ( $\mathrm{F}$ 1s region) & [45] \\
\hline & $\mathrm{Nb}$ & $203.1[3 \mathrm{~d} 5 / 2] ; 205.9$ [3d5/2] (Nb 3d region) & This work \\
\hline & $\mathrm{Nb}-\mathrm{C}^{\mathrm{V}}$ & 282.3 (C 1s region) & This work \\
\hline & $\mathrm{Nb}^{*}$ & $203.5[3 \mathrm{~d} 5 / 2] ; 206.3[3 \mathrm{~d} 3 / 2](\mathrm{Nb} 3 \mathrm{~d}$ region) & {$[46,47]$} \\
\hline \multirow{2}{*}{ IV } & $\mathrm{H}_{2} \mathrm{O}_{\text {ads }}[$ Ti-case $]$ & 533.3 (O 1s region) & {$[43]$} \\
\hline & $\mathrm{H}_{2} \mathrm{O}_{\text {ads }}[\mathrm{Nb}$-case $]$ & 533.3 (O 1s region) & This work \\
\hline
\end{tabular}

$\$ \mathrm{Nb}$ near a $\mathrm{C}$ vacancy

*Interior $\mathrm{Nb}$ bound to only $\mathrm{C}$ (no surface terminations)

${ }^{\mathrm{v}} \mathrm{C}$ bound to $\mathrm{Nb}^{*}$ 
The $\mathrm{M}$ atoms that are bonded to $\mathrm{C}$ atoms alone $-e . g$. those in the central layers of the $n>1$ MXene flakes - will be referred to by an asterisk, or $\mathrm{M}^{*}$. In the Ti case, we could not differentiate between moiety $\mathrm{I}$ and $\mathrm{Ti}^{*}$ atoms and thus both are labeled $\mathrm{I}$. In the $\mathrm{Nb}_{4} \mathrm{C}_{3} \mathrm{~T}_{\mathrm{x}}$ case, there was a clear distinction between the $\mathrm{Nb}^{*}$ atoms and moiety I. However, one complication with the $\mathrm{Nb}$-containing MXenes is $\mathrm{Ar}$ beam damage. A peak - possibly emanating from a $\mathrm{Nb}$ atom bonded to one less $\mathrm{C}$-atom than its neighbors - will henceforth be referred to as $\mathrm{Nb} \ddagger$. A peak arising from a $\mathrm{C}$ atom bonded to $\mathrm{Nb} \ddagger$ and next to a vacant $\mathrm{C}$ site will henceforth be referred to as $\mathrm{Nb}-\mathrm{C}^{\mathrm{v}}$. The fraction of the latter species after sputtering was $<10$ $\%$.

To recapitulate, for the Ti flakes, the following moieties were assumed to exist: I, II, III and IV. For the $\mathrm{Nb}$ compositions, moieties I, II, III, IV, $\mathrm{Nb}^{*}, \mathrm{Nb}^{\mathrm{V}}$ and $\mathrm{Nb} \ddagger$ (after sputtering only) were invoked. Table 1 lists the energies associated with each termination. In addition a number of peaks associated with $\mathrm{TiO}_{2}$ and $\mathrm{Nb}_{2} \mathrm{O}_{5}$, as separate species due to oxidation were also identified. We also identified $\mathrm{M}$ atoms that are bonded to $\mathrm{O}$ atoms alone - i.e. in oxide form - that are, in turn, bonded to a $\mathrm{F}$-atom, i.e. $\mathrm{TiO}_{2-\mathrm{x}} \mathrm{F}_{\mathrm{x}}$ or $\mathrm{NbO}_{1-\mathrm{x}} \mathrm{F}_{\mathrm{x}}$, as separate oxyfluoride species. It is with this in mind that we stress that the sheer chemical complexity (from internal moieties, adventitious organic species to oxidation products) of MXene systems can cause ambiguity within spectra. The existence of so many chemical species necessitates the inclusion of a large number of fitting components in XPS analysis in order to account for their presence. Having established these fitting schemes as a robust system has advantages, however, since as shown here it allows us to track any shifts in surface terminations, such as oxidation, with time.

\section{Results}

At the outset, it is important to note that some binary carbide impurity phases were present in the initial MAX phase powders. Based on XRD patterns of the parent MAX phases (not shown) we estimate that 15 mole $\%$ TiC impurity phase was present in $\mathrm{Ti}_{2} \mathrm{AlC} ; 15$ mole $\%$ of $\mathrm{TiCN}$ in $\mathrm{Ti}_{3} \mathrm{AlCN} ; 20$ mole $\%$ of $\mathrm{Nb}_{4} \mathrm{AlC}_{3}$ in $\mathrm{Nb}_{2} \mathrm{AlC}$ and 5 mole $\%$ of $\mathrm{NbC}$ in $\mathrm{Nb}_{4} \mathrm{AlC}_{3}$. In all results reported herein, the presence of these 
binary carbides were accounted for, and subtracted from the chemical compositions more details are found in supplementary materials S3.

Since the most important contribution of this work is assigning - in a comprehensive and consistent manner - the various energy peaks to different moieties, in this section we focus on the component peakfitting (deconvolution) of XPS spectra for the pre- and post-sputter cleaned ap- $\mathrm{Ti}_{3} \mathrm{C}_{2} \mathrm{~T}_{\mathrm{x}}$ and the sputtercleaned ag- $\mathrm{Nb}_{4} \mathrm{C}_{3} \mathrm{~T}_{\mathrm{x}}$ as being representative of the chemical species present in all MXenes studied herein. The XPS spectra and peak-fits for the other MXenes can be found in supplementary material (See Section S5). In addition, we measured the XPS spectra of all parent MAX phases after sputtering (see Supplementary material section S6 and Figures S12 to S16).

\section{1. $\mathrm{Ti}_{3} \mathrm{C}_{2} T_{x}$ (Figure 2; Tables 2 and 3)}

Figures 2a-d plot, respectively, the spectra for Ti, C, O and F for pre-sputter-cleaned $a p-\mathrm{Ti}_{3} \mathrm{C}_{2} \mathrm{~T}_{\mathrm{x}}$, together with their peak-fits. The respective spectra, after sputtering, are plotted in Figures 2 e-g. The peak positions obtained from the fits are summarized in Tables 2 and 3 for the pre- and post-sputtered ap$\mathrm{Ti}_{3} \mathrm{C}_{2} \mathrm{~T}_{\mathrm{x}}$ samples, respectively.

3.1.1. Ti $2 p$ region. The Ti $2 p$ region for the pre-sputtered ap- $\mathrm{Ti}_{3} \mathrm{C}_{2} \mathrm{~T}_{\mathrm{x}}$ sample (Figure $2 \mathrm{a}$ ), was fit by the components listed in column 5 in Table 2 . The majority of the species are $\mathrm{Ti}$ atoms $\left(\mathrm{Ti}, \mathrm{Ti}^{2+}, \mathrm{Ti}^{3+}\right)$, that belong to moieties I, II, and/or IV and $\mathrm{Ti}_{3} \mathrm{C}_{2} \mathrm{~F}_{\mathrm{x}}$, viz. moiety III. These comprise $93 \%$ of the photoemission in the Ti $2 \mathrm{p}$ region. The same region, for the sputtered ap- $\mathrm{Ti}_{3} \mathrm{C}_{2} \mathrm{~T}_{\mathrm{x}}$ sample (Figure $2 \mathrm{e}$, Table 2), was fit by the same moities (I, II, and/or IV, and III). In this case, they comprise $98 \%$ of the photoemission in the Ti $2 \mathrm{p}$ region. It is worth noting that similar oxidation states for $\mathrm{Ti}$ reported here, viz. $\mathrm{Ti}^{2+}$ and $\mathrm{Ti}^{3+}$, were reported for TiC.[48]

For the pre-sputtered ag- $\mathrm{Ti}_{3} \mathrm{C}_{2} \mathrm{~T}_{\mathrm{x}}$ sample (see Figure S2, Table S3), the moieties I, II, or IV, and III comprise $77 \%$ of the $\mathrm{Ti} 2 \mathrm{p}$ region photoemission. After sputtering they comprise $83 \%$ (see Figure S3, 
Table S4). In other words, for the pre-sputtered ag- $\mathrm{Ti}_{3} \mathrm{C}_{2} \mathrm{~T}_{\mathrm{x}}$ sample, almost a quarter of the Ti $2 \mathrm{p}$ region belongs to $\mathrm{TiO}_{2}$ and $\mathrm{TiO}_{2-\mathrm{x}} \mathrm{F}_{\mathrm{x}}$. This percentage decreases slightly after sputtering.

Note that the $\mathrm{BE}$ of the $\mathrm{Ti} 2 \mathrm{p}_{3 / 2}$ peaks in the ap- $\mathrm{Ti}_{3} \mathrm{C}_{2} \mathrm{~T}_{\mathrm{x}}$ sample decreases slightly, from $455.0 \mathrm{eV}$ to $454.8 \mathrm{eV}$, upon sputtering. This decrease might be due to the introduction of defects and/or incorporated Ar ions due to sputtering, which is a commonly observed for transition metal carbides. [49] For the ag$\mathrm{Ti}_{3} \mathrm{C}_{2} \mathrm{~T}_{\mathrm{x}}$ sample, the BE decreases from $455.2 \mathrm{eV}$ to $454.9 \mathrm{eV}$ upon sputtering. Note that the pre-sputtered $\mathrm{BE}$ of this peak increased by $0.2 \mathrm{eV}$ after aging the sample, indicative of the removal of electron density as the sample oxidized.

In general, the BEs for the Ti peaks of the $\mathrm{Ti}_{3} \mathrm{C}_{2} \mathrm{~T}_{\mathrm{x}}$ samples $(\approx 455 \mathrm{eV})$, are higher than the $454.6 \mathrm{eV}$ value in the parent MAX phase, $\mathrm{Ti}_{3} \mathrm{AlC}_{2}$ (Figure S13a).[50] This shift is due to the replacement of the $\mathrm{Al}$ layers by more electronegative surface terminations such as $\mathrm{O}, \mathrm{OH}$ and $\mathrm{F}$.

3.1.2. $C 1$ s region. The $\mathrm{C} 1 \mathrm{~s}$ region (Figure $2 \mathrm{~b}$ ) of the pre-sputtered ap- $\mathrm{Ti}_{3} \mathrm{C}_{2} \mathrm{~T}_{\mathrm{x}}$ sample was fit by three peaks. The largest $\left(\approx 54 \%\right.$ of the $\mathrm{C} 1 \mathrm{~s}$ region), at a BE of $282.0 \mathrm{eV}$, corresponds to C-Ti- $\mathrm{T}_{\mathrm{x}}$ (moieties I, II, III, and/or IV). After sputtering, the BEs do not change (compare Figure $2 b$ and Figure 2f), but the fraction of this peak, however, increases from $54 \%$ to $85 \%$ after sputtering. Its energy is slightly higher than that of $\mathrm{C}$ in $\mathrm{Ti}_{3} \mathrm{AlC}_{2}(281.5-281.8 \mathrm{eV})$ [50] (see also Figure $\mathrm{S} 13 \mathrm{~b}$ ). This can possibly be attributed to defects introduced in the Ti-C layers due to the etching procedure.

The other two peaks correspond to graphitic $\mathrm{C}-\mathrm{C}$ and $\mathrm{CH}_{\mathrm{x}}$ or $\mathrm{C}-\mathrm{O}$ (Figures $2 \mathrm{~b}$ and $2 \mathrm{f}$ and Tables 2 and 3). The former could be due to selective dissolution of Ti during etching, which can result in graphitic C$\mathrm{C}$ formation.[51] The $\mathrm{CH}_{\mathrm{x}}$, and $\mathrm{C}-\mathrm{O}$ species, on the other hand, likely result from the solvents used in the separation and drying processes and/or the exposure of the high-surface area material to the ambient. Note that the percentages of $\mathrm{C}-\mathrm{C}, \mathrm{CH}_{\mathrm{x}}$ and $\mathrm{C}-\mathrm{O}$ decrease to about $15 \%$ of the photoemission in the $\mathrm{C} 1 \mathrm{~s}$ region for the ap- $\mathrm{Ti}_{3} \mathrm{C}_{2} \mathrm{~T}_{\mathrm{x}}$ sample after sputtering. Not surprisingly, the concentration of these species (69\%) in 
the ag- $\mathrm{Ti}_{3} \mathrm{C}_{2} \mathrm{~T}_{\mathrm{x}}$ sample before sputtering is the highest. That value drops to $13 \%$ after sputtering (See Supplementary materials S5.2),

3.1.3. $O$ 1s region. The $\mathrm{O} 1 \mathrm{~s}$ region for the pre-sputtered ap- $\mathrm{Ti}_{3} \mathrm{C}_{2} \mathrm{~T}_{\mathrm{x}}$ sample (Figure 2c), was fit by components corresponding to C-Ti- $\mathrm{O}_{x}$ (moiety I), C-Ti- $(\mathrm{OH})_{\mathrm{x}}$ (moiety II), and $\mathrm{H}_{2} \mathrm{O}_{\text {ads }}$ (moiety IV), which are the majority fractions (53\%) of that region. The balance is in the form of $\mathrm{TiO}_{2}, \mathrm{TiO}_{2-\mathrm{x}} \mathrm{F}$, and $\mathrm{Al}_{2} \mathrm{O}_{3}$ (Column 5 in Table 2). After sputtering, the total fraction of the latter is reduced to $29 \%$. Sputtering does not affect any of the BEs of the oxygen species in the ap- $\mathrm{Ti}_{3} \mathrm{C}_{2} \mathrm{~T}_{\mathrm{x}}$ sample.

The $\mathrm{O}$ 1s region for the pre-sputtered ag- $\mathrm{Ti}_{3} \mathrm{C}_{2} \mathrm{~T}_{\mathrm{x}}$ sample (Figure $\mathrm{S} 2 \mathrm{c}$ ) was fit by the same components as above. However, in this case the content of $\mathrm{TiO}_{2}, \mathrm{TiO}_{2-\mathrm{x}} \mathrm{F}_{\mathrm{x}}$ and $\mathrm{Al}_{2} \mathrm{O}_{3}$ is $31 \%$. (Column 4 in Table $\mathrm{S} 3$ ). A large contribution to this region is from organic contamination, which overlaps with, and obscures, many other peaks. After sputtering, the total fraction of these oxides increases slightly to $34 \%$, largely because of the removal of organic contamination. Sputtering does not affect any of the BEs of the oxygen species in the ap- $\mathrm{Ti}_{3} \mathrm{C}_{2} \mathrm{~T}_{\mathrm{x}}$ sample.

The BEs of moiety $I$ in the ap- $\mathrm{Ti}_{3} \mathrm{C}_{2} \mathrm{~T}_{\mathrm{x}}$ and ag- $\mathrm{Ti}_{3} \mathrm{C}_{2} \mathrm{~T}_{\mathrm{x}}$ samples, before and after sputtering, ranged from 531 to $531.3 \mathrm{eV}$. These values are close to those of an $\mathrm{O}$ atom near to a vacant site in $\mathrm{TiO}_{2}$, i.e. a defective $\mathrm{TiO}_{2}(531.5 \mathrm{eV})$.[43] The peak for moiety II is located at BEs ranging from 531.7 to $532 \mathrm{eV}$, which is quite close to that of $\mathrm{OH}$ groups at bridging sites on $\mathrm{TiO}_{2}$. [43] The binding energy for moiety II shifts to a lower BEs upon aging and/or sputtering, which indicates that the local environment of such species is changed upon aging and/or sputtering

As discussed above, the $\mathrm{H}_{2} \mathrm{O}_{\text {ads }}$ component (moiety IV) reflects the aqueous nature of the production of MXenes. The $\mathrm{BE}$ of its peak, for the pre- and post-sputtered ap- $\mathrm{Ti}_{3} \mathrm{C}_{2} \mathrm{~T}_{\mathrm{x}}-$ at 533.8 and $533.7 \mathrm{eV}$, respectively - are quite close to each other and to that of water adsorbed on titania (533.5 eV).[43] This $\mathrm{BE}$ is higher than that for the same component in the ag- $\mathrm{Ti}_{3} \mathrm{C}_{2} \mathrm{~T}_{\mathrm{x}}$ sample pre- and post-sputtering, which are at 533.2 and $533.3 \mathrm{eV}$, respectively, (see Figures S2c and S3c and Tables S3 and S4). This species has 
been observed for $\mathrm{Ti}_{3} \mathrm{C}_{2} \mathrm{~T}_{\mathrm{x}}$, as well as other MXenes such as $\mathrm{Nb}_{2} \mathrm{CT}_{\mathrm{x}}$ and $\mathrm{V}_{2} \mathrm{CT}_{\mathrm{x}}$. [22, 52] The $\mathrm{Al}(\mathrm{OF})_{\mathrm{x}}$ species, present in ap- $\mathrm{Ti}_{3} \mathrm{C}_{2} \mathrm{~T}_{\mathrm{x}}$ after sputtering, and ag- $\mathrm{Ti}_{3} \mathrm{C}_{2} \mathrm{~T}_{\mathrm{x}}$ before, and after, sputtering is present as a by-product of the synthesis procedure. The presence of $\mathrm{Al}(\mathrm{OF})_{\mathrm{x}}$ after sputtering in ap- $\mathrm{Ti}_{3} \mathrm{C}_{2} \mathrm{~T}_{\mathrm{x}}$ probably reflects inhomogeneities in the etched powders and/or less than perfect washing.

No useful quantitative information - as opposed to BEs - could be obtained from the O XPS spectra of the aged samples before sputtering because the fitted peaks in the $531 \mathrm{eV}$ to $534 \mathrm{eV} \mathrm{BE}$ range overlaped with those of other organic compounds [53] whose concentration is non-trivial.

3.1.4. F 1 s region. The major component in the F 1 s region (Figure $2 \mathrm{~d}$ ) prior to sputtering for the ap$\mathrm{Ti}_{3} \mathrm{C}_{2} \mathrm{~T}_{\mathrm{x}}$ sample was C-Ti- $\mathrm{F}_{\mathrm{x}}$ (i.e. moiety III in Figure 1) at a $\mathrm{BE}$ of $685.0 \mathrm{eV}$. This $\mathrm{BE}$ is $0.1 \mathrm{eV}$ higher than that of $\mathrm{TiF}_{4},[54]$ a similar compound that should have a value close to that of the $\mathrm{Ti}-\mathrm{F}$ bond in $\mathrm{Ti}_{3} \mathrm{C}_{2} \mathrm{~F}_{\mathrm{x}}$. After sputtering, the BE increases to $685.2 \mathrm{eV}$ (Figure $2 \mathrm{~h}$, and Table 3 ).

Before sputtering of the ag- $\mathrm{Ti}_{3} \mathrm{C}_{2} \mathrm{~T}_{\mathrm{x}}$ sample, the BE of moiety III drops $0.2 \mathrm{eV}$ (Figure S2d and Table S3). After sputtering, the BE of this moiety, is identical to that of the ap- $\mathrm{Ti}_{3} \mathrm{C}_{2} \mathrm{~T}_{\mathrm{x}}$ (Figure $2 \mathrm{~d}$ and Table 2). All samples contained small fractions of $\mathrm{TiO}_{2-\mathrm{x}} \mathrm{F}_{\mathrm{x}}, \mathrm{AlF}_{\mathrm{x}}$ and $\mathrm{Al}(\mathrm{OF})_{\mathrm{x}}$ (Tables 2, 3, S3 and S4). The latter two are present as byproducts of the synthesis procedure, and their presence was confirmed by high-resolution XPS spectra in the Al $2 p$ region (Figure $\mathrm{S} 2 \mathrm{e}$ ). 

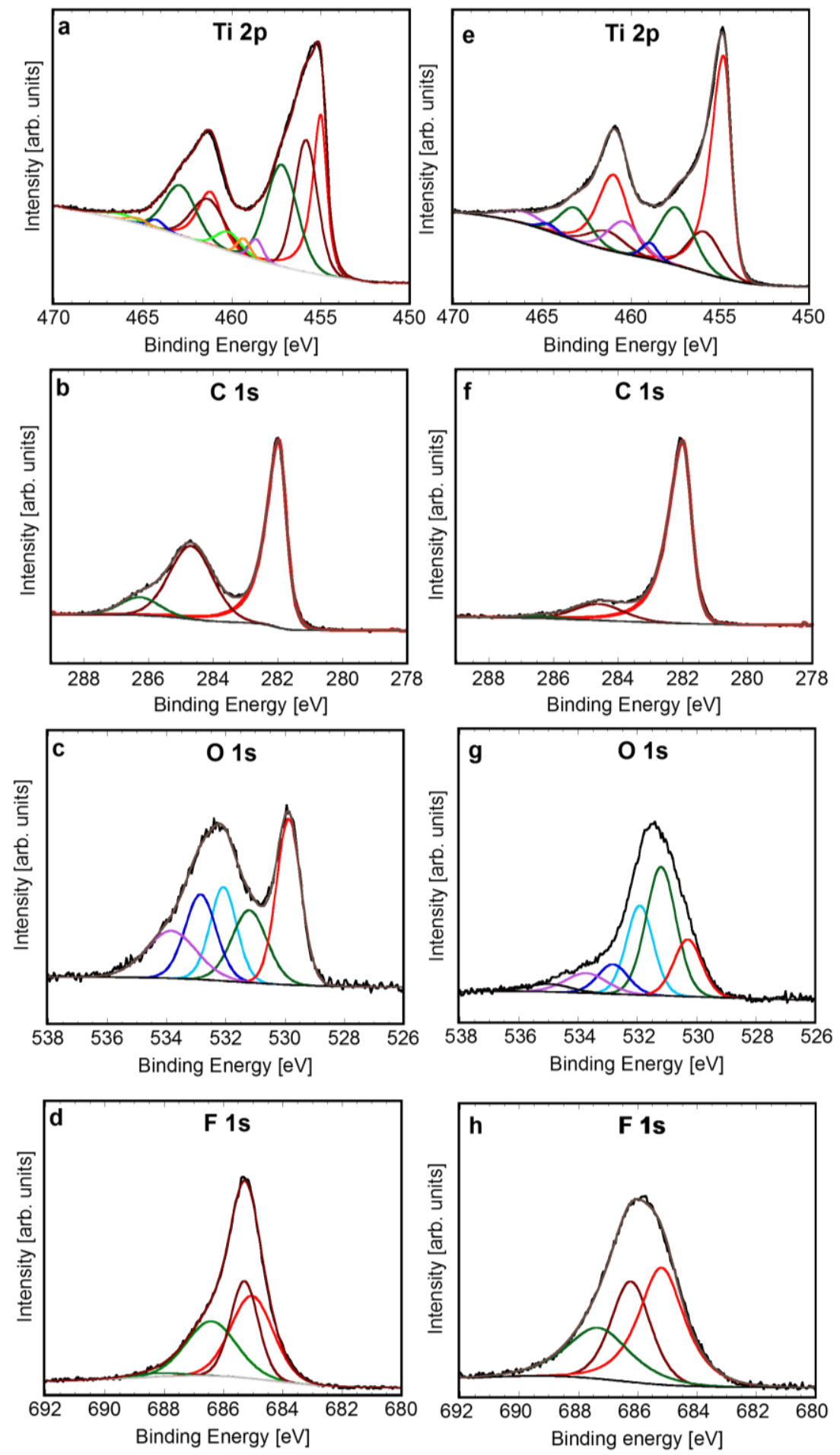

Figure 2. Component peak-fitting of XPS spectra for ap- $\mathrm{Ti}_{3} \mathrm{C}_{2} \mathrm{~T}_{\mathrm{x}}$, (a) Ti 2p, (b) C 1s, (c) O 1s, and (d) F 1s before sputtering and, (e) Ti 2p, (f) C 1s, (g) O 1s and, (h) F 1s after sputtering. The various peaks under the spectra represent various moieties assumed to exist. The results are summarized in Tables 2 and 3 for the pre and postsputtering samples, respectively. 
Table 2. XPS peak fitting results for ap- $\mathrm{Ti}_{3} \mathrm{C}_{2} \mathrm{~T}_{\mathrm{x}}$ before sputtering. The numbers in brackets in column 2 are peak locations of Ti 2 $\mathrm{p}_{1 / 2}$; their respective full-widths at half maximum, FWHM, are listed in column 3 in brackets.

\begin{tabular}{|c|c|c|c|c|c|}
\hline Region & $\mathrm{BE}[\mathrm{eV}]^{\mathrm{a}}$ & FWHM $[\mathrm{eV}]^{\mathrm{a}}$ & Fraction & Assigned to & Reference \\
\hline \multirow{6}{*}{$\operatorname{Ti} 2 \mathrm{p}_{3 / 2}\left(2 \mathrm{p}_{1 / 2}\right)$} & $455.0(461.2)$ & $0.8(1.5)$ & 0.28 & $\mathrm{Ti}(\mathrm{I}, \mathrm{II}$ or IV) & $\overline{[48,50]}$ \\
\hline & $455.8(461.3)$ & $1.5(2.2)$ & 0.30 & $\mathrm{Ti}^{2+}(\mathrm{I}, \mathrm{II}$, or IV) & [48] \\
\hline & $457.2(462.9)$ & $2.1(2.1)$ & 0.32 & $\mathrm{Ti}^{3+}(\mathrm{I}, \mathrm{II}$, or IV) & [48] \\
\hline & $458.6(464.2)$ & $0.9(1.0)$ & 0.02 & $\mathrm{TiO}_{2}$ & {$[55,56]$} \\
\hline & $459.3(465.3)$ & $0.9(1.4)$ & 0.03 & $\mathrm{TiO}_{2-\mathrm{x}} \mathrm{F}_{\mathrm{x}}$ & {$[57]$} \\
\hline & $460.2(466.2)$ & $1.6(2.7)$ & 0.05 & $\mathrm{C}-\mathrm{Ti}-\mathrm{F}_{\mathrm{x}}(\mathrm{IIII})$ & {$[54]$} \\
\hline \multirow{3}{*}{$\mathrm{C} 1 \mathrm{~s}$} & 282.0 & 0.6 & 0.54 & C-Ti-T $(\mathrm{I}, \mathrm{II}, \mathrm{III}$, or IV) & {$[48,50]$} \\
\hline & 284.7 & 1.6 & 0.38 & $\mathrm{C}-\mathrm{C}$ & [58] \\
\hline & 286.3 & 1.4 & 0.08 & $\mathrm{CH}_{\mathrm{x}} / \mathrm{C}-\mathrm{O}$ & [58] \\
\hline \multirow{5}{*}{$\mathrm{O} 1 \mathrm{~s}$} & 529.9 & 1.0 & 0.29 & $\mathrm{TiO}_{2}$ & {$[43,56]$} \\
\hline & 531.2 & 1.4 & 0.18 & $\mathrm{C}-\mathrm{Ti}^{-} \mathrm{O}_{\mathrm{x}}(\mathrm{I})$ and/or OR ${ }^{\mathrm{b}}$ & {$[43,53]$} \\
\hline & 532.0 & 1.1 & 0.18 & $\mathrm{C}-\mathrm{Ti}-(\mathrm{OH})_{\mathrm{x}}(\mathrm{II})$ and/or $\mathrm{OR}^{\mathrm{b}}$ & {$[43,53]$} \\
\hline & 532.8 & 1.2 & 0.19 & $\mathrm{Al}_{2} \mathrm{O}_{3}$ and/or $\mathrm{OR}^{\mathrm{b}}$ & {$[53,59,60]$} \\
\hline & 533.8 & 2.0 & 0.17 & $\mathrm{H}_{2} \mathrm{O}_{\text {ads }}(\mathrm{IV})$ and/or $\mathrm{OR}^{\mathrm{b}}$ & {$[43,53]$} \\
\hline \multirow{4}{*}{ F 1s } & 685.0 & 1.7 & 0.38 & C-Ti-F $($ III) & {$[54]$} \\
\hline & 685.3 & 1.1 & 0.29 & $\mathrm{TiO}_{2-\mathrm{x}} \mathrm{F}_{\mathrm{x}}$ & [57] \\
\hline & 686.4 & 2.0 & 0.30 & $\mathrm{AlF}_{\mathrm{x}}$ & [57] \\
\hline & 688.3 & 2.0 & 0.02 & $\mathrm{Al}(\mathrm{OF})_{\mathrm{x}}$ & [59] \\
\hline
\end{tabular}

\footnotetext{
${ }^{\mathrm{a}}$ Values in parenthesis correspond to the $2 \mathrm{p}_{1 / 2}$ component.

${ }^{\mathrm{b}}$ OR stands for organic compounds due to atmospheric surface contaminations.
} 
Table 3. XPS peak fitting results for ap- $\mathrm{Ti}_{3} \mathrm{C}_{2} \mathrm{~T}_{\mathrm{x}}$ after sputtering. Numbers in brackets in column 2 are peak locations of Ti $2 \mathrm{p}_{1 / 2}$; their full-widths at half maximum, FWHM, are listed in column 3 in brackets.

\begin{tabular}{|c|c|c|c|c|c|}
\hline Region & $\mathrm{BE}[\mathrm{eV}]$ & FWHM [eV] & Fraction & Assigned to & Reference \\
\hline \multirow{5}{*}{$\operatorname{Ti} 2 \mathrm{p}_{3 / 2}\left(2 \mathrm{p}_{1 / 2}\right)$} & $454.8(461.0)$ & $1.0(1.9)$ & 0.52 & $\mathrm{Ti}(\mathrm{I}, \mathrm{II}$ or IV) & {$[48,50]$} \\
\hline & $455.9(461.5)$ & $2.2(2.4)$ & 0.14 & $\mathrm{Ti}^{2+}(\mathrm{I}, \mathrm{II}$, or IV) & [48] \\
\hline & $457.5(463.2)$ & $2.3(2.0)$ & 0.21 & $\mathrm{Ti}^{3+}(\mathrm{I}, \mathrm{II}$, or IV $)$ & [48] \\
\hline & $459.0(464.7)$ & $1.0(1.1)$ & 0.02 & $\mathrm{TiO}_{2}$ & {$[55,56]$} \\
\hline & $460.4(466.1)$ & $2.1(2.9)$ & 0.11 & C-Ti-F $F_{x}(\mathrm{III})$ & [44] \\
\hline \multirow{3}{*}{$\mathrm{C} 1 \mathrm{~s}$} & 282.0 & 0.6 & 0.85 & C-Ti-T $x$ (I, II,III, or IV) & {$[48,50]$} \\
\hline & 284.6 & 0.18 & 0.14 & $\mathrm{C}-\mathrm{C}$ & [58] \\
\hline & 286.5 & 1.4 & 0.01 & $\mathrm{C} 0 . \mathrm{H}_{\mathrm{x}} / \mathrm{C}-\mathrm{O}$ & [58] \\
\hline \multirow{6}{*}{$\mathrm{O} 1 \mathrm{~s}$} & 530.3 & 1.1 & 0.16 & $\mathrm{TiO}_{2}$ & {$[43,56]$} \\
\hline & 531.2 & 1.2 & 0.39 & $\mathrm{C}-\mathrm{Ti}-\mathrm{O}_{\mathrm{x}}(\mathrm{I})$ and/or $\mathrm{OR}^{\mathrm{b}}$ & {$[43,53]$} \\
\hline & 531.9 & 1.1 & 0.24 & C-Ti- $(\mathrm{OH})_{\mathrm{x}}(\mathrm{II})$ and/or $\mathrm{OR}^{\mathrm{b}}$ & {$[43,53]$} \\
\hline & 532.8 & 1.2 & 0.09 & $\mathrm{Al}_{2} \mathrm{O}_{3}$ and/or $\mathrm{OR}^{\mathrm{b}}$ & {$[53,59,60]$} \\
\hline & 533.7 & 1.7 & 0.08 & $\mathrm{H}_{2} \mathrm{O}_{\text {ads }}(\mathrm{IV})$ and/or $\mathrm{OR}^{\mathrm{b}}$ & {$[43,53]$} \\
\hline & 534.9 & 1.7 & 0.04 & $\mathrm{Al}(\mathrm{OF})_{\mathrm{x}}$ & [59] \\
\hline \multirow{3}{*}{ F 1s } & 685.2 & 1.8 & 0.44 & C-Ti-F $($ III) & {$[44]$} \\
\hline & 686.2 & 1.6 & 0.30 & $\mathrm{AlF}_{\mathrm{x}}$ & [59] \\
\hline & 687.3 & 2.5 & 0.26 & $\mathrm{Al}(\mathrm{OF})_{\mathrm{x}}$ & [59] \\
\hline
\end{tabular}

\footnotetext{
${ }^{a}$ Values in parenthesis correspond to the $2 \mathrm{p}_{1 / 2}$ component.

${ }^{\mathrm{b}}$ OR stands for organic compounds due to atmospheric surface contaminations.
}

\section{2. $a g-\mathrm{Nb}_{4} \mathrm{C}_{3} T_{x}$ (Figure 3; Table 4)}

Figures $4 \mathrm{a}$ to $\mathrm{d}$ plot the post-sputtered spectra for $\mathrm{Nb}, \mathrm{C}, \mathrm{O}$ and $\mathrm{F}$, respectively, in the ag- $\mathrm{Nb}_{4} \mathrm{C}_{3} \mathrm{~T}_{\mathrm{x}}$ sample, together with their peak fits. The results are summarized in Table 4.

3.2.1. $\mathrm{Nb} 3 d$ region. The XPS spectra of this region (Figure 3a) were fit by the corresponding components listed in column 5 in Table 4: $\mathrm{Nb} \ddagger, \mathrm{Nb}^{*}, \mathrm{Nb}$ (moieties I, II, and/or IV), and C-Nb-F (moiety III). These species comprised $86 \%$ of the photoemission in the region, while the rest is assigned to the various oxides, $\mathrm{NbO}, \mathrm{NbO}_{2}, \mathrm{NbO}_{1-\mathrm{x}} \mathrm{F}_{\mathrm{x}}$ and $\mathrm{Nb}_{2} \mathrm{O}_{5}$ and a nearly negligible unidentified component at a $\mathrm{BE}$ of 209.2 $\mathrm{eV}$ (only $1 \%$ of photoemission), which could be due to the effect of Ar sputtering. 
The peak assigned to moieties I, II and/or IV has a BE of $203.8 \mathrm{eV}$, which is $0.4 \mathrm{eV}$ lower than to its counterpart in $\mathrm{Nb}_{4} \mathrm{AlC}_{3}$ (Figure $\mathrm{S} 17 \mathrm{a}$ ) and is $0.1 \mathrm{eV}$ lower than of its counterpart in NbC.[46, 47] Since this species corresponds to the two outer $\mathrm{Nb}$ layers, this decrease in $\mathrm{BE}$ is, again, due to the replacement of the Al layers by more electronegative surface terminations.[46] Conversely, the peak attributed to the two inner metal atom layers $\left(\mathrm{Nb}^{*}\right)$ has a $\mathrm{BE}$ of $203.5 \mathrm{eV}$, which is $0.2 \mathrm{eV}$ lower than that of its $\mathrm{NbC}$ counterpart $(203.7 \mathrm{eV})$. This somewhat unexpected result suggests that the inner $\mathrm{Nb}$ atoms in $\mathrm{Nb}_{4} \mathrm{C}_{3} \mathrm{~T}_{\mathrm{x}}$ take on additional electron density as compared to those in $\mathrm{NbC}$.

Both inner and outer $\mathrm{Nb}$ species exist before sputtering (Supplementary materials section S5.4, Figures S5 and Table S7). However, after sputtering a peak appears at a lower BE $(203.1 \mathrm{eV})$, that was not present before. This peak can thus be attributed to sputter damage of $\mathrm{Nb}$ and/or $\mathrm{Nb}^{*}$.

3.2.2. $C 1$ s region. The $\mathrm{C} 1 \mathrm{~s}$ region (Figure $3 \mathrm{~b}$ ) was fit by components corresponding to $\mathrm{Nb}-\mathrm{C}^{\mathrm{v}}, \mathrm{C}-\mathrm{Nb}-\mathrm{T}_{\mathrm{x}}$ (I, II, or IV) and small fractions for graphitic $\mathrm{C}-\mathrm{C}$ and $\mathrm{CH}_{\mathrm{x}}$. The peak corresponding to $\mathrm{Nb}-\mathrm{C}$ (I, II, III and/or IV) has a $\mathrm{BE}$ of $282.8 \mathrm{eV}$, which is slightly higher than that of $\mathrm{Nb}_{4} \mathrm{AlC}_{3}(282.7 \mathrm{eV})$ (Figure $\mathrm{S} 16 \mathrm{~b}$ ) and $\mathrm{NbC}(281.8 \mathrm{eV}) .[61]$ A peak at a lower $\mathrm{BE}(282.3 \mathrm{eV})$ is also present before, and after, sputtering, which can be attributed to a $\mathrm{C}$ near a vacancy, or defect, site $\left(\mathrm{Nb}-\mathrm{C}^{\mathrm{v}}\right)$.

3.2.3. O 1s region. The spectra in this region (Figure 3c) were fit by components corresponding to $\mathrm{C}-\mathrm{Nb}-$ $\mathrm{O}_{\mathrm{x}}$ (moiety I, $\left.531.0 \mathrm{eV}\right), \mathrm{C}-\mathrm{Nb}-(\mathrm{OH})_{\mathrm{x}}$ (moiety II, $531.6 \mathrm{eV}$ ) and $\mathrm{H}_{2} \mathrm{O}_{\text {ads }}$ (moiety IV, $533.3 \mathrm{eV}$ ). These species comprise $68 \%$ of the $\mathrm{O} 1 \mathrm{~s}$ region photoemission (Table 5). Note that the $\mathrm{H}_{2} \mathrm{O}_{\text {ads }}$ peak position is located quite close to the same species discussed above for $\mathrm{Ti}_{3} \mathrm{C}_{2} \mathrm{~T}_{\mathrm{x}}$, lending credence its assignment. The remainder of the photoemission is fit by components corresponding to oxides of $\mathrm{Nb}_{2} \mathrm{O}_{5}(530.5 \mathrm{eV}), \mathrm{Al}_{2} \mathrm{O}_{3}$ $(532.4 \mathrm{eV})$ and oxyfluorides of $\mathrm{Al}(\mathrm{OF})_{\mathrm{x}}(534.7 \mathrm{eV}) .[59,60,62-64]$ These species are a result of surface oxidation and/or are by-products of the synthesis. 
3.2.4. F 1 s region. The spectra in this region (Figure $3 \mathrm{~d}$ ) were fit by a peak corresponding to $\mathrm{C}-\mathrm{Nb}-\mathrm{F}_{\mathrm{x}}$ (moiety III) that comprised $75 \%$ of the photoemission for the region. The other $25 \%$ of photoemission was fit by components for $\mathrm{NbO}_{1-\mathrm{x}} \mathrm{F}_{\mathrm{x}}$ and $\mathrm{AlF}_{\mathrm{x}}$ (Table 4). The peak assigned to moiety III sits at a $\mathrm{BE}$ of $685.3 \mathrm{eV}$, which is slightly higher than the $\mathrm{F} 1 \mathrm{~s}$ peak value for $\mathrm{NbF}_{5 .}[45]$ The peak for $\mathrm{NbO}_{1-\mathrm{x}} \mathrm{F}_{\mathrm{x}}$ is at $684.0 \mathrm{eV}$. The presence of $\mathrm{AlF}_{\mathrm{x}}$ is confirmed by the appearance of a peak for this species in the $\mathrm{Al} 2 \mathrm{p}$ region (Figure S6).
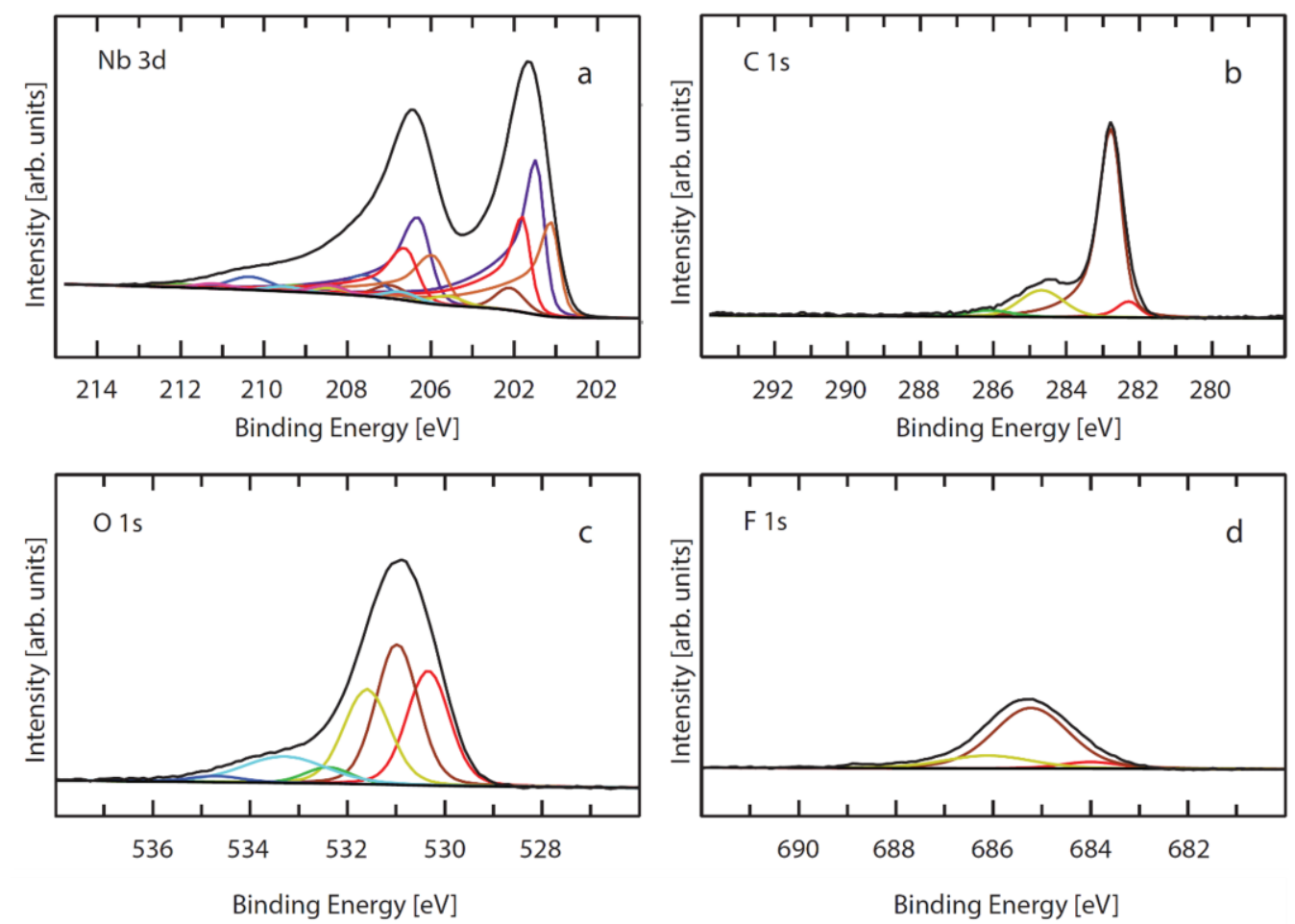

Figure 3. Post $\mathrm{Ar}^{+}$-sputtering component peak-fitting of XPS spectra for, (a) $\mathrm{Nb} 3 \mathrm{~d}$, (b) C 1s, (c) O 1s and, (d) F 1s for ag- $\mathrm{Nb}_{4} \mathrm{C}_{3} \mathrm{~T}_{\mathrm{x}}$ sample. The various peaks represent various moieties assumed to exist. The results, after sputtering, are summarized in Table 4. 
Table 4. XPS peak fitting of results - shown in Figure 3 - for ag- $-\mathrm{Nb}_{4} \mathrm{C}_{3} \mathrm{~T}_{\mathrm{x}}$ after sputtering. The numbers in brackets

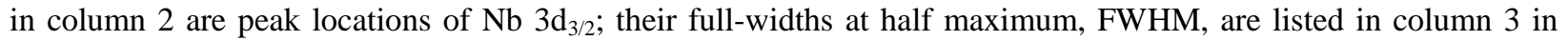
brackets.

\begin{tabular}{|c|c|c|c|c|c|}
\hline Region & $\mathrm{BE}[\mathrm{eV}]^{\mathrm{a}}$ & FWHM [eV] & Fraction & Assigned to & Reference \\
\hline \multirow{8}{*}{$\mathrm{Nb} 3 \mathrm{~d}_{5 / 2}\left(3 \mathrm{~d}_{3 / 2}\right)$} & $203.1(205.9)$ & $0.5(0.7)$ & 0.23 & $\mathrm{Nb} \ddagger$ & \\
\hline & $203.5(206.3)$ & $0.5(0.7)$ & 0.38 & $\mathrm{Nb}^{*}$ & \\
\hline & $203.8(206.6)$ & $0.5(0.7)$ & 0.23 & $\mathrm{Nb}(\mathrm{I}, \mathrm{II}$, or IV) & {$[46,47]$} \\
\hline & $204.1(206.9)$ & $0.8(0.9)$ & 0.04 & $\mathrm{NbO}$ & {$[46,65,66]$} \\
\hline & $205.6(208.4)$ & $0.9(1.0)$ & 0.02 & $\mathrm{Nb}(3+)-\mathrm{O}$ & \\
\hline & $206.7(209.5)$ & $0.9(1.0)$ & 0.02 & $\mathrm{Nb}(4+)-\mathrm{O}$ & {$[46,65,66]$} \\
\hline & $207.6(210.4)$ & $0.9(1.0)$ & 0.05 & $\mathrm{Nb}_{2} \mathrm{O}_{5}$ & {$[46,65,66]$} \\
\hline & $208.4(211.2)$ & $1.1(1.2)$ & 0.02 & C-Nb-Fx (III) & {$[45,66]$} \\
\hline \multirow{4}{*}{$\mathrm{C} 1 \mathrm{~s}$} & 282.3 & $\overline{0.7}$ & $\overline{0.06}$ & $\mathrm{Nb}-\mathrm{C}^{\mathrm{v}}$ & \\
\hline & 282.8 & 0.7 & 0.74 & $\mathrm{Nb}-\mathrm{C}$ & [61] \\
\hline & 284.7 & 2.0 & 0.16 & $\mathrm{C}-\mathrm{C}$ & [58] \\
\hline & 286.1 & 2.0 & 0.04 & $\mathrm{CH}_{\mathrm{x}}$ & [58] \\
\hline \multirow{6}{*}{$\mathrm{O} 1 \mathrm{~s}$} & 530.5 & 1.0 & 0.26 & $\overline{\mathrm{Nb}_{2} \mathrm{O}_{5}}$ & [62-64] \\
\hline & 531.0 & 1.0 & 0.32 & $\mathrm{C}-\mathrm{Nb}-\mathrm{O}_{\mathrm{x}}(\mathrm{I})$ & \\
\hline & 531.6 & 1.1 & 0.24 & $\mathrm{C}-\mathrm{Nb}-(\mathrm{OH})_{\mathrm{x}}(\mathrm{II})$ & \\
\hline & 532.4 & 1.1 & 0.04 & $\mathrm{Al}_{2} \mathrm{O}_{3}$ & {$[59,60]$} \\
\hline & 533.3 & 2.0 & 0.12 & $\mathrm{H}_{2} \mathrm{O}_{\text {ads }}(\mathrm{IV})$ & \\
\hline & 534.7 & 1.3 & 0.02 & $\mathrm{Al}(\mathrm{OF})_{\mathrm{x}}$ & [59] \\
\hline \multirow{3}{*}{$\mathrm{F} 1 \mathrm{~s}$} & 684.0 & 1.4 & 0.06 & $\mathrm{NbO}_{1-\mathrm{x}} \mathrm{F}_{\mathrm{x}}$ & \\
\hline & 685.3 & 1.4 & 0.75 & C-Nb-F $\mathrm{F}_{\mathrm{x}}$ (III) & [45] \\
\hline & 686.1 & 2.1 & 0.19 & $\mathrm{AlF}_{\mathrm{x}}$ & [59] \\
\hline
\end{tabular}

${ }^{a}$ Values in parenthesis correspond to the $3 \mathrm{~d}_{3 / 2}$ component.

\subsection{Distributions of Terminations}

Figure 4 plots the post-sputtered moles of the various $\mathrm{T}_{\mathrm{x}}$ species (as derived from the fits of the nonmetal spectral regions) per MXene formula unit (as derived from the fits of the metal spectral regions) for all samples examined herein. These same results, including the $\mathrm{C}$-content, are also presented in Table 5 as chemical formulas. A perusal of these results shows that: 
a) Before sputtering, most of the $\mathrm{OH}$-terminations have adsorbed $\mathrm{H}_{2} \mathrm{O}$ associated with them, i.e. moiety IV (yellow in Fig. 4) is prevalent. Sputtering and aging increase moiety II (grey in Fig. 4) at the expense of moiety IV.

b) The fraction of F-terminations - moiety III (red in Fig. 4) - is highest for the un-sputtered, freshly prepared samples. Sputtering and aging combined with sputtering increase moieties II and IV (hatched regions in Fig. 4) at the expense of moiety III. Note that the grey and blue colored crosshatched regions in Fig. 4 represent $\mathrm{OH}$-terminations.

c) The fraction of moiety I (blue in Fig. 4) for the as-prepared, un-sputtered Ti-containing MXenes is about 0.3. Sputtering and aging combined with sputtering increase that fraction significantly. For example, in the $\mathrm{Ti}_{3} \mathrm{C}_{2} \mathrm{~T}_{\mathrm{x}}$ case, moiety $\mathrm{I}$ is doubled after sputtering. As noted above, aging and sputtering increase the $\mathrm{OH}$-terminations at the expense of the F-terminations. A fraction of these $\mathrm{OH}$-terminations are, in turn, strongly bonded to $\mathrm{H}_{2} \mathrm{O}$ water molecules (blue hatched regions in Figure 4). About 22 to 33 mole $\%$ of the Ti atoms are terminated with oxygen atoms (blue) and $\approx$ 17 mole $\%$ are F-terminated (red).

d) Replacing $50 \%$ of the $\mathrm{C}$ atoms by $\mathrm{N}$ atoms, led to a decrease in moiety $\mathrm{I}$, a slight decrease moiety III and a concomitant increase in OH-terminations (compare ag- $\mathrm{Ti}_{3} \mathrm{C}_{2} \mathrm{~T}_{\mathrm{x}}$ and ag- $\mathrm{Ti}_{3} \mathrm{CNT}_{\mathrm{x}}$ in Fig. 4).

e) For the un-sputtered, fresh, Nb-based MXenes, the major effect of increasing $n$, is the presence of a significantly higher fraction of the hydroxyl terminations (Table 5). For the Ti-based MXenes, increasing $n$, results in an increase in moiety I, while the combined total of moieties II and IV remains approximately the same.

f) For the un-sputtered, ap- $\mathrm{Nb}_{4} \mathrm{C}_{3} \mathrm{~T}_{\mathrm{x}}$ composition, the total number of moles for all terminations exceeds the maximum possible value of 2 (see Fig. 1b)- assuming one termination per surface M atom - by 0.6 moles.[67] The reason for this surface state is unclear, but it is possible that some of the terminating atoms end up occupying $\mathrm{C}$-vacancy sites. In this MXene, the fraction of $-\mathrm{O}$ (blue 
region in Figure 4), $-\mathrm{F}$ (orange region in Figure 4) and OH-terminations (hatched regions in Figure 4) are roughly equal.

g) The fraction of oxygen terminations (moiety I) is highest in $\mathrm{Nb}_{2} \mathrm{CT}_{\mathrm{x}}$ (blue regions in Figure 4). Those in $\mathrm{Nb}_{4} \mathrm{C}_{3} \mathrm{~T}_{\mathrm{x}}$ are comparable to their Ti counterparts (compare blue regions in Figure 4). Interestingly, a majority of the $\mathrm{OH}$-terminations in $\mathrm{Nb}_{2} \mathrm{CT}_{\mathrm{x}}$ have strongly bonded water molecules attached to them.

h) With the notable exceptions of ap- $\mathrm{Ti}_{3} \mathrm{C}_{2} \mathrm{~T}_{\mathrm{x}}$ and ag- $-\mathrm{Nb}_{4} \mathrm{C}_{3} \mathrm{~T}_{\mathrm{x}}$, the fraction of F-terminations (orange regions in Fig. 4) is significantly lower than their $-\mathrm{O}$ or $-\mathrm{OH}$ counterparts.

i) With the exception of the $\mathrm{Ti}_{2} \mathrm{CT}_{\mathrm{x}}$-based MXene, the general effect of sputtering is to decrease the $\mathrm{X}$ content below the value measured for the un-sputtered samples of the same composition. For example, the sputtered ap- $\mathrm{Ti}_{3} \mathrm{C}_{2} \mathrm{~T}_{\mathrm{x}}$ and ap- $\mathrm{Ti}_{3} \mathrm{CNT}_{\mathrm{x}}$ sample are $10 \%$ deficient in $\mathrm{X}$; and the sputtered ap- $\mathrm{Nb}_{4} \mathrm{C}_{3} \mathrm{~T}_{\mathrm{x}}$ composition the $\mathrm{C}$ content drops from 2.6 to 2.4 after sputtering. As described below in the Discussion section, this is due to $\mathrm{Ar}^{+}$ion beam damage, which selectively sputters $\mathrm{C}$ and $\mathrm{N}$ atoms from the lattice.

j) Finally, aging seems to reverse the aforementioned trend. In all cases, the X-deficiency after aging and sputtering is less than directly after sputtering of the fresh samples. 


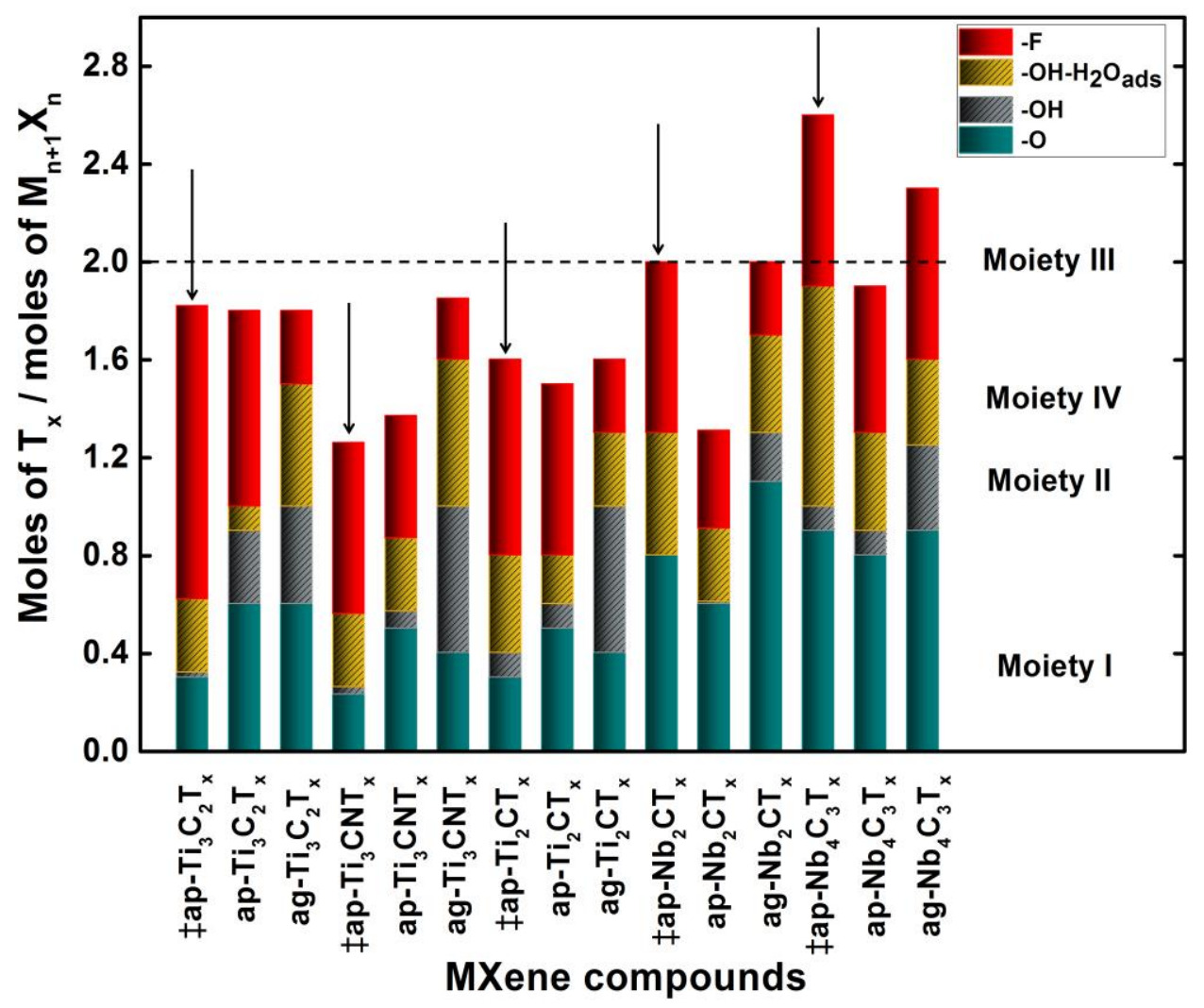

Figure 4. Ratio of moles of terminations per $\mathrm{M}_{\mathrm{n}+1} \mathrm{X}_{\mathrm{n}}$ formula unit, obtained herein. The results obtained for columns labeled by arrows were obtained before sputtering; all the rest after Ar sputtering. The formulas for before sputtering are marked with $\ddagger$. Both as-prepared, ap, and after aging, ag, samples are shown. The hatched regions represent the total fraction of $\mathrm{OH}$ terminations; the ones with $\mathrm{H}_{2} \mathrm{O}$ adsorbed are depicted in yellow. Note that if one termination is assumed per $\mathrm{M}$ atom, then in all cases the theoretical $\mathrm{T}_{\mathrm{x}}$ number per formula unit is 2 given by the horizontal dashed line. 
Table 5. Summary of results obtained in this work. Entries labeled $\ddagger$ were determined from spectra before sputtering. The net negative charges on the terminations - assuming the charges on the oxygen atoms are - 2, those on $\mathrm{F}$ and $\mathrm{OH},-1-$ are shown in brackets below the formulas.

\begin{tabular}{|c|c|c|}
\hline $\mathrm{M}_{2} \mathrm{XT}_{\mathrm{x}}$ & $\mathrm{M}_{3} \mathrm{X}_{2} \mathrm{~T}_{\mathrm{x}}$ & $\mathrm{M}_{4} \mathrm{X}_{3} \mathrm{~T}_{\mathrm{x}}$ \\
\hline $\begin{array}{c}\text { + ap- } \mathrm{Ti}_{2} \mathrm{C}_{0.9} \mathrm{O}_{0.3}(\mathrm{OH})_{0.1}\left(\mathrm{OH}-\mathrm{H}_{2} \mathrm{O}_{\mathrm{ads}}\right)_{0.4} \mathrm{~F}_{0.8} \\
(1.9)\end{array}$ & $\begin{array}{c}\$ \text { ap- } \mathrm{Ti}_{3} \mathrm{C}_{2} \mathrm{O}_{0.3}(\mathrm{OH})_{0.02}\left(\mathrm{OH}-\mathrm{H}_{2} \mathrm{O}_{\mathrm{ads}}\right)_{0.3} \mathrm{~F}_{1.2} \\
(2.12)\end{array}$ & $\begin{array}{c}\$ \text { ap- } \mathrm{Nb}_{4} \mathrm{C}_{2.6} \mathrm{O}_{0.9}(\mathrm{OH})_{0.1}\left(\mathrm{OH}-\mathrm{H}_{2} \mathrm{O}_{\text {ads }}\right)_{0.9} \mathrm{~F}_{0.7} \\
(3.5)\end{array}$ \\
\hline $\begin{array}{c}\text { ap- } \mathrm{Ti}_{2} \mathrm{C}_{0.9} \mathrm{O}_{0.5}(\mathrm{OH})_{0.1}\left(\mathrm{OH}-\mathrm{H}_{2} \mathrm{O}_{\mathrm{ads}}\right)_{0.2} \mathrm{~F}_{0.7} \\
(2.0)\end{array}$ & $\begin{array}{c}\text { ap- } \mathrm{Ti}_{3} \mathrm{C}_{1.8} \mathrm{O}_{0.6}(\mathrm{OH})_{0.3}\left(\mathrm{OH}-\mathrm{H}_{2} \mathrm{O}_{\text {ads }}\right)_{0.1} \mathrm{~F}_{0.8} \\
(2.4)\end{array}$ & $\begin{array}{c}\text { ap- } \mathrm{Nb}_{4} \mathrm{C}_{2.4} \mathrm{O}_{0.8}(\mathrm{OH})_{0.1}\left(\mathrm{OH}-\mathrm{H}_{2} \mathrm{O}_{\mathrm{ads}}\right)_{0.4} \mathrm{~F}_{0.6} \\
(2.7)\end{array}$ \\
\hline $\begin{array}{c}\text { ag- } \mathrm{Ti}_{2} \mathrm{C}_{0.8} \mathrm{O}_{0.4}(\mathrm{OH})_{0.6}\left(\mathrm{OH}-\mathrm{H}_{2} \mathrm{O}_{\mathrm{ads}}\right)_{0.3} \mathrm{~F}_{0.3} \\
(2.0)\end{array}$ & $\begin{array}{c}\text { ag- } \mathrm{Ti}_{3} \mathrm{C}_{1.8} \mathrm{O}_{0.6}(\mathrm{OH})_{0.4}\left(\mathrm{OH}-\mathrm{H}_{2} \mathrm{O}_{\text {ads }}\right)_{0.5} \mathrm{~F}_{0.3} \\
(2.4)\end{array}$ & $\begin{array}{c}\text { ag- } \mathrm{Nb}_{4} \mathrm{C}_{2.3} \mathrm{O}_{0.9}(\mathrm{OH})_{0.35}\left(\mathrm{OH}-\mathrm{H}_{2} \mathrm{O}_{\text {ads }}\right)_{0.35} \mathrm{~F}_{0.7} \\
(3.2)\end{array}$ \\
\hline $\begin{array}{c}\$ \mathrm{ap}-\mathrm{Nb}_{2} \mathrm{CO}_{0.8}\left(\mathrm{OH}-\mathrm{H}_{2} \mathrm{O}_{\text {ads }}\right)_{0.5} \mathrm{~F}_{0.7} \\
(2.8)\end{array}$ & $\begin{array}{c}\$ \text { ap- } \mathrm{Ti}_{3} \mathrm{CNO}_{0.23}(\mathrm{OH})_{0.03}\left(\mathrm{OH}-\mathrm{H}_{2} \mathrm{O}_{\mathrm{ads}}\right)_{0.3} \mathrm{~F}_{1.3} \\
(2.09)\end{array}$ & \\
\hline $\begin{array}{c}\text { ap- } \mathrm{Nb}_{2} \mathrm{C}_{0.9} \mathrm{O}_{0.6}(\mathrm{OH})_{0.01}\left(\mathrm{OH}-\mathrm{H}_{2} \mathrm{O}_{\text {ads }}\right)_{0.3} \mathrm{~F}_{0.4} \\
(1.91)\end{array}$ & $\begin{array}{c}\text { ap- } \mathrm{Ti}_{3} \mathrm{C}_{0.9} \mathrm{~N}_{0.9} \mathrm{O}_{0.5}(\mathrm{OH})_{0.07}\left(\mathrm{OH}-\mathrm{H}_{2} \mathrm{O}_{\text {ads }}\right)_{0.3} \mathrm{~F}_{0.5} \\
(1.87)\end{array}$ & \\
\hline $\begin{array}{c}\mathrm{ag}-\mathrm{Nb}_{2} \mathrm{CO}_{1.1}(\mathrm{OH})_{0.2}\left(\mathrm{OH}-\mathrm{H}_{2} \mathrm{O}_{\mathrm{ads}}\right)_{0.4} \mathrm{~F}_{0.3} \\
(3.1)\end{array}$ & $\begin{array}{c}\mathrm{ag}-\mathrm{Ti}_{3} \mathrm{C}_{0.6} \mathrm{~N}_{0.8} \mathrm{O}_{0.4}(\mathrm{OH})_{0.6}\left(\mathrm{OH}-\mathrm{H}_{2} \mathrm{O}_{\text {ads }}\right)_{0.6} \mathrm{~F}_{0.25} \\
(2.25)\end{array}$ & \\
\hline
\end{tabular}

\$ Before sputtering.

\subsection{Global Chemistries and Effect of Sputtering}

Table 6 summarizes the global chemistries (including non-MXene species) as deduced from the XPS spectra, before and after sputtering. The most notable trend seen in these results is the reduction - by $\approx 50 \%$ in some cases - of the $\mathrm{C}$ signal and the subsequent increase in the $\mathrm{M}$ signal upon sputtering. For example, for the ag- $\mathrm{Ti}_{3} \mathrm{C}_{2} \mathrm{~T}_{\mathrm{x}}$ sample, the Ti percentage increased from about 17 at.\% before sputtering to 28 at.\% after sputtering; concomitantly, the $\mathrm{C}$ percentage decreased from 33 to 16 at.\%. 
Table 6. Summary of global atomic percentages - including non-MXene entities - before and after sputtering.

\begin{tabular}{|c|c|c|c|c|c|c|c|}
\hline & $\mathrm{Ti}$ at $\%$ & $\mathrm{Nb}$ at. $\%$ & $\mathrm{C}$ at.\% & $\mathrm{F}$ at. $\%$ & $\mathrm{O}$ at. $\%$ & $\mathrm{Al}$ at. $\%$ & $\mathrm{~N}$ at. $\%$ \\
\hline ap- $\mathrm{Ti}_{3} \mathrm{C}_{2} \mathrm{~T}_{\mathrm{x}}$ (before) & $26.1 \pm 0.1$ & & $31.4 \pm 0.2$ & $25.5 \pm 0.2$ & $15.1 \pm 0.2$ & $1.9 \pm 0.1$ & $<0.1$ \\
\hline ap- $\mathrm{Ti}_{3} \mathrm{C}_{2} \mathrm{~T}_{\mathrm{x}}$ (after) & $34.1 \pm 0.2$ & & $23.7 \pm 0.3$ & $20.9 \pm 0.2$ & $18.0 \pm 0.2$ & $3.3 \pm 0.2$ & $<0.1$ \\
\hline ag- $\mathrm{Ti}_{3} \mathrm{C}_{2} \mathrm{~T}_{\mathrm{x}}$ (before) & $16.8 \pm 0.3$ & & $33.4 \pm 0.5$ & $24.8 \pm 0.4$ & $20.1 \pm 0.4$ & $3.3 \pm 0.6$ & $1.6 \pm 0.3$ \\
\hline ag- $\mathrm{Ti}_{3} \mathrm{C}_{2} \mathrm{~T}_{\mathrm{x}}$ (after) & $28.4 \pm 0.5$ & & $16.2 \pm 0.7$ & $24.0 \pm 0.5$ & $26.4 \pm 0.5$ & $4.2 \pm 0.6$ & $<0.1$ \\
\hline ap- $\mathrm{Ti}_{2} \mathrm{CT}_{\mathrm{x}}$ (before) & $27.2 \pm 0.9$ & & $39.4 \pm 0.9$ & $13.4 \pm 0.6$ & $20.0 \pm 0.7$ & $<0.1$ & $<0.1$ \\
\hline ap- $\mathrm{Ti}_{2} \mathrm{CT}_{\mathrm{x}}$ (after) & $33.4 \pm 0.9$ & & $29.5 \pm 0.9$ & $13.7 \pm 0.7$ & $23.4 \pm 0.9$ & $<0.1$ & $<0.1$ \\
\hline ag- $\mathrm{Ti}_{2} \mathrm{CT}_{\mathrm{x}}$ (before) & $19.3 \pm 0.3$ & & $31.1 \pm 0.6$ & $11.4 \pm 0.4$ & $34.9 \pm 0.6$ & $1.2 \pm 0.7$ & $<0.1$ \\
\hline ag- $\mathrm{Ti}_{2} \mathrm{CT}_{\mathrm{x}}$ (after) & $33.7 \pm 0.5$ & & $15.8 \pm 0.7$ & $11.8 \pm 0.5$ & $35.5 \pm 0.6$ & $1.9 \pm 0.7$ & $1.3 \pm 0.3$ \\
\hline ap- $\mathrm{Ti}_{3} \mathrm{CNT}_{\mathrm{x}}$ (before) & $30.6 \pm 1.8$ & & $29.4 \pm 1.1$ & $16.1 \pm 0.8$ & $12.1 \pm 0.7$ & $<0.1$ & $11.8 \pm 0.6$ \\
\hline ap- $\mathrm{Ti}_{3} \mathrm{CNT}_{\mathrm{x}}$ (after) & $36.5 \pm 1.5$ & & $18.8 \pm 1.0$ & $13.4 \pm 0.7$ & $18.3 \pm 1.0$ & $<0.1$ & $12.9 \pm 0.7$ \\
\hline ag- $\mathrm{Ti}_{3} \mathrm{CNT}_{\mathrm{x}}$ (before) & $20.5 \pm 0.3$ & & $20.1 \pm 0.6$ & $13.4 \pm 0.5$ & $38.0 \pm 0.6$ & $1.9 \pm 0.5$ & $6.1 \pm 0.4$ \\
\hline ag- $\mathrm{Ti}_{3} \mathrm{CNT}_{\mathrm{x}}$ (after) & $32.8 \pm 0.5$ & & $9.3 \pm 0.6$ & $15.1 \pm 0.5$ & $31.3 \pm 0.6$ & $1.5 \pm 0.7$ & $10.0 \pm 0.5$ \\
\hline ap- $\mathrm{Nb}_{2} \mathrm{CT}_{\mathrm{x}}$ (before) & & $25.0 \pm 0.7$ & $31.4 \pm 0.9$ & $12.6 \pm 0.6$ & $31.0 \pm 0.8$ & $<0.1$ & $<0.1$ \\
\hline ap- $\mathrm{Nb}_{2} \mathrm{CT}_{\mathrm{x}}$ (after) & & $42.5 \pm 0.9$ & $24.3 \pm 1.1$ & $11.7 \pm 0.5$ & $35.1 \pm 0.8$ & $<0.1$ & $<0.1$ \\
\hline ag- $\mathrm{Nb}_{2} \mathrm{CT}_{\mathrm{x}}$ (before) & & $16.0 \pm 0.3$ & $33.6 \pm 0.8$ & $15.1 \pm 0.5$ & $32.6 \pm 0.6$ & $1.2 \pm 0.5$ & $1.5 \pm 0.6$ \\
\hline $\mathrm{ag}-\mathrm{Nb}_{2} \mathrm{CT}_{\mathrm{x}}$ (after) & & $38.8 \pm 0.5$ & $21.0 \pm 1.0$ & $9.5 \pm 0.5$ & $28.3 \pm 0.7$ & $1.4 \pm 0.6$ & $<0.1$ \\
\hline ap- $-\mathrm{Nb}_{4} \mathrm{C}_{3} \mathrm{~T}_{\mathrm{x}}$ (before) & & $25.3 \pm 0.2$ & $55.0 \pm 1.0$ & $4.2 \pm 0.6$ & $15.5 \pm 0.7$ & $<0.1$ & $<0.1$ \\
\hline $\mathrm{ap}-\mathrm{Nb}_{4} \mathrm{C}_{3} \mathrm{~T}_{\mathrm{x}}$ (after) & & $29.7 \pm 0.4$ & $52.3 \pm 0.6$ & $3.6 \pm 0.4$ & $14.4 \pm 0.5$ & $<0.1$ & $<0.1$ \\
\hline ag- $-\mathrm{Nb}_{4} \mathrm{C}_{3} \mathrm{~T}_{\mathrm{x}}$ (before) & & $10.8 \pm 0.2$ & $36.0 \pm 1.0$ & $21.7 \pm 0.6$ & $26.3 \pm 0.7$ & $5.0 \pm 1.5$ & $<0.1$ \\
\hline ag- $\mathrm{Nb}_{4} \mathrm{C}_{3} \mathrm{~T}_{\mathrm{x}}$ (after) & & $39.9 \pm 0.5$ & $24.4 \pm 0.7$ & $7.3 \pm 0.3$ & $24.7 \pm 0.5$ & $3.7 \pm 0.6$ & $<0.1$ \\
\hline
\end{tabular}

Spectra collected before sputtering for the fresh MXenes in this study show that the M:X ratio is the same as the theoretical ratio for all MXenes except $\mathrm{Ti}_{2} \mathrm{CT}_{\mathrm{x}}$ has a $\mathrm{M}: \mathrm{X}$ ratio of 2:0.9 (10\% deficiency in X). This deficiency might be due to preferential HF-etching of the X element. After sputtering of fresh MXene samples, an increase in the M:X ratio is observed for all MXenes (except $\mathrm{Ti}_{2} \mathrm{CT}_{\mathrm{x}}$ ) which is due to $\mathrm{Ar}^{+}$ion beam damage, selectively sputtering $\mathrm{C}$ atoms from the lattice. After sputtering, the aged MXenes in this study exhibit a further increase in the M:X ratio, compared to the fresh sputtered samples.. For example, ag- $\mathrm{Ti}_{2} \mathrm{CT}_{\mathrm{x}}$ has a $\mathrm{M}: \mathrm{X}$ ratio of 2:0.8 (20\% deficiency in $\left.\mathrm{X}\right), \mathrm{ag}-\mathrm{Ti}_{3} \mathrm{CNT}_{\mathrm{x}}$ has a $\mathrm{M}: \mathrm{X}$ ratio of 3:1.2 
(40\% deficiency in $\mathrm{X}$ ), and ag- $\mathrm{Nb}_{4} \mathrm{C}_{3} \mathrm{~T}_{\mathrm{x}}$ has a $\mathrm{M}: \mathrm{X}$ ratio of $4: 2.3$ (40\% deficiency in $\mathrm{X}$ ). This change in ratio may be attributable to a replacement of some of the $\mathrm{C}$ atoms in the MXenes sheets by $\mathrm{O}$ during oxidation.

To further explore the effect of sputtering, the moles of $\mathrm{C}$ and moles - per formula unit - of moieties I, II, III and IV in ap- $\mathrm{Ti}_{3} \mathrm{C}_{2} \mathrm{~T}_{\mathrm{x}}$, before and after $\mathrm{Ar}^{+}$sputtering are plotted in Figure 5. From these results it is obvious that the F-content is also reduced, with a concomitant increase in moiety I. There is also a decrease in the moles of $\mathrm{H}_{2} \mathrm{O}$ strongly adsorbed to the surface, i.e. moiety IV, (see Figure 5). The same tendency can also be gleaned from comparing the derived formulae before $\left[\mathrm{Ti}_{3} \mathrm{C}_{2} \mathrm{O}_{0.3}(\mathrm{OH})_{0.32} \mathrm{~F}_{1.2}\right]$ and after $\left[\mathrm{Ti}_{3} \mathrm{C}_{1.8} \mathrm{O}_{0.6}(\mathrm{OH})_{0.4} \mathrm{~F}_{0.8}\right]$ sputtering. It is thus obvious that the reduction in moiety III is accompanied with an increase in moiety I. Said otherwise, neither the C-atoms in ap- $\mathrm{Ti}_{3} \mathrm{C}_{2} \mathrm{~T}_{\mathrm{x}}$ nor the F-terminations i.e. moiety III - are immune to the sputtering procedure used in this work. The same analysis of other compositions is not possible, due to organic (ambient) contamination obscuring relevant peaks, however a similar trend would be expected. Whether the entirety of the increase in M:F is due to preferential $-\mathrm{F}$ sputtering, or has some contribution from a decreased concentration of $-\mathrm{F}$ on the interior of the MXenes is unclear. Regardless, the C- and F-contents of sputtered samples reported herein most probably underestimate their true values. 


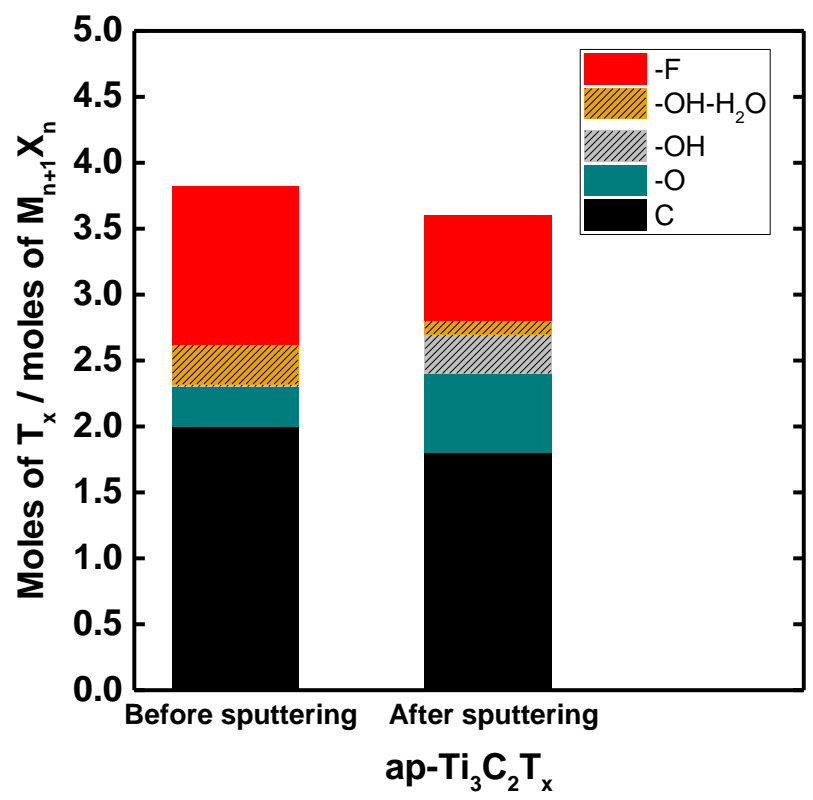

Figure 5. Number of moles of $\mathrm{C}$ and moles of moieties I, II, III and IV, per $\mathrm{Ti}_{3} \mathrm{C}_{2} \mathrm{~T}_{\mathrm{x}}$ formula unit, for the ap$\mathrm{Ti}_{3} \mathrm{C}_{2} \mathrm{~T}_{\mathrm{x}}$ sample before, and after, Ar sputtering.

The effects of sputtering on the fraction of the various oxides present in the various MXenes are plotted in Figures S18 and S19. From these results it is clear that sputtering decreases the total fraction of Ti oxides and oxyflourides in the Ti-containing compositions (Figure S18) and the $\mathrm{Nb}$ oxides and oxyflourides in the Nb-containing compositions (Figure S19). Some MXenes appear to be more prone to oxidation than others. For example, sputter cleaning ag- $\mathrm{Ti}_{3} \mathrm{CNT}_{\mathrm{x}}$ decreased the fraction of oxides from $88.3 \%$ to about $50.2 \%$, compared to fractions of $48.3 \%$ and $34.6 \%$ for the ag- $\mathrm{Ti}_{3} \mathrm{C}_{2} \mathrm{~T}_{\mathrm{x}}$ sample. No clear correlation was found between oxidation susceptibility and $n$ or M.

Figures S20a and b plot the atomic percentages of the various $\mathrm{C}$ species in the ap- and ag- $\mathrm{Ti}_{3} \mathrm{C}_{2} \mathrm{~T}_{\mathrm{x}}$ samples before, and after, sputtering, respectively. From these results it is clear that the atomic percentages of the $\mathrm{C}$-species associated with the ap- $\mathrm{Ti}_{3} \mathrm{C}_{2} \mathrm{~T}_{\mathrm{x}} \mathrm{MXene}$ structure, increase from $~ 54$ at. $\%$ before, to $\sim 85$ at.\% after sputtering (Tables 2 and 3, Figure S20a). In the case of the aged sample, the respective values are $~ 31$ at.\% to $\sim 87$ at.\% (Tables S3 and S4, Figure S20b). We note that the presence of a thin adventitious $\mathrm{C}$ film on the outermost surfaces of our pressed discs that were stored in air for a 
relatively long time is not too surprising. This is all confirmed by the fact that the fraction of adventitious $\mathrm{C}$ and hydrocarbons for the ap- $\mathrm{Ti}_{3} \mathrm{C}_{2} \mathrm{~T}_{\mathrm{x}}$ sample before sputtering was only $10 \%$; after sputtering it was < $1 \%$. For all other MXenes the adventitious $\mathrm{C}$ and hydrocarbons concentrations were $<2 \%$ after sputtering.

The effects of aging on the samples are demonstrated in Tables 5 and 6 . It can be seen in Table 5 that upon aging, the amount of $-\mathrm{F}$ terminations are reduced for all of the MXenes, except $\mathrm{Nb}_{4} \mathrm{C}_{3} \mathrm{~T}_{\mathrm{x}}$, which stays the same. Concomitantly, the amount of $-\mathrm{OH}$ terminations are increased for all of the MXenes during aging. When viewed from a stoichiometric perspective, the $\mathrm{M}: \mathrm{O}$ ratio (with the $\mathrm{O}$ content derived from the sum of moieties I, II and IV) decreases for all of the MXenes as they age (Table 5). For example, the $\mathrm{M}: \mathrm{O}$ ratio for ap- $\mathrm{Ti}_{3} \mathrm{C}_{2} \mathrm{~T}_{\mathrm{x}}$ is 3:1, while the $\mathrm{M}: \mathrm{O}$ ratio for ag- $\mathrm{Ti}_{3} \mathrm{C}_{2} \mathrm{~T}_{\mathrm{x}}$ is $3: 1.5$. These data indicate that as MXenes age, the surface chemistry changes as $-\mathrm{F}$ groups are predominately replaced with $-\mathrm{OH}$ groups. Note also, that the total number of moles for the various terminations gradually increases over time, indicating that oxidation of the MXenes begins as surface functionalization. As more evidence for this trend, the global (including non-MXene species) M:O ratio also decreases from 3:1.6 for ap $-\mathrm{Ti}_{3} \mathrm{C}_{2} \mathrm{~T}_{\mathrm{x}}$ to 3:2.8 for ag- $\mathrm{Ti}_{3} \mathrm{C}_{2} \mathrm{~T}_{\mathrm{x}}$ (Table 6). The change in the global $\mathrm{M}: \mathrm{O}$ ratio for these samples indicates the uptake of oxygen over time as oxides are formed. Similar trends occur for all of the MXenes, though again, some show to be more prone to oxidation than others. For example, the global M:O ratio for ap$\mathrm{Ti}_{2} \mathrm{CT}_{\mathrm{x}}$ is $3: 2.1$ while the ratio for $\mathrm{ag}-\mathrm{Ti}_{2} \mathrm{CT}_{\mathrm{x}}$ is $1: 1.05$. The fact that these trends are seen for all MXenes, however, clearly indicates the surface chemistry and global changes due to aging are processes that are ubiquitous.

Combined with the observation that sputtering decreases the amount of oxides, the oxygen and carbon data help to illustrate the overall framework of the aged MXene samples, wherein the MXene sits at the center of the grain, surrounded by a thin layer of oxides, which is then coated in a C-film. Graphitic carbon is present as a synthetic by-product as well, and likely helps to maintain conductive contact 
between MXene particles. The comparison between as-prepared and aged samples demonstrates that the use of MXene shortly after synthesis greatly reduces the amount of oxides and adventitious carbon present.

\section{Discussion}

Based on the totality of the results, summarized in Fig. 4 and Table 5, we conclude that the overall formulas for the Ti-containing MXenes - calculated without including the $\mathrm{TiO}_{2}$ and other known oxide fractions - are $\mathrm{Ti}_{3} \mathrm{C}_{2} \mathrm{O}_{0.3}(\mathrm{OH})_{0.32} \mathrm{~F}_{1.2}$ and $\mathrm{Ti}_{3} \mathrm{C}_{1.8} \mathrm{O}_{0.6}(\mathrm{OH})_{0.4} \mathrm{~F}_{0.8}$ for ap- $\mathrm{Ti}_{3} \mathrm{C}_{2} \mathrm{~T}_{\mathrm{x}}$, before and after sputtering, respectively. For the sputtered samples measured after aging in air, the formulas are: $\mathrm{Ti}_{3} \mathrm{C}_{1.8} \mathrm{O}_{0.6}(\mathrm{OH})_{0.9} \mathrm{~F}_{0.3}, \mathrm{Ti}_{2} \mathrm{C}_{0.8} \mathrm{O}_{0.4}(\mathrm{OH})_{0.9} \mathrm{~F}_{0.3}$ and $\mathrm{Ti}_{3} \mathrm{C}_{0.6} \mathrm{~N}_{0.8} \mathrm{O}_{0.4}(\mathrm{OH})_{1.2} \mathrm{~F}_{0.25}$. Interestingly, if one assumes the charge of $-\mathrm{O}$ is -2 , and those of $-\mathrm{F}$ and $-\mathrm{OH}$ are -1 , then the average net negative charges on the surface terminations - shown in brackets below the formulas in Table 4 - for the Ti-based compounds are 2.15 \pm 0.2 . In case of the $\mathrm{Nb}$-containing MXenes, the average value is $2.9 \pm 0.6$. This is an important result because it suggests that the $M_{n+1} X_{n}$ surface layers have a fixed net positive charge to which the composition of surface terminations must adjust to compensate and result in a neutral structure.

Recent XANES measurements have shown that the $\mathrm{Ti}_{3} \mathrm{C}_{2} \mathrm{~T}_{\mathrm{x}}$ spectra as quite comparable to those of $\mathrm{TiO}$ and that the average oxidation state of the Ti atoms was $\approx 2.4$.[68] Using this value - and assuming the oxidation states of the $-\mathrm{O},-\mathrm{OH}$ and $-\mathrm{F}$ groups to be $-2,-1$ and -1 , respectively - one can solve for the average oxidation states of the $\mathrm{C}$ atoms. Using the results shown in Table 4 , the average $\mathrm{C}$ oxidation state in $\mathrm{Ti}_{3} \mathrm{C}_{2} \mathrm{~T}_{\mathrm{x}}$ is $-2.6 \pm 0.1$. Why these are the favored oxidation states is not clear at this time, but is a fruitful area of research for theoreticians. Similar calculations for the other compositions must await XANES measurements to determine the average $\mathrm{M}$ oxidation states.

From the results shown in Figure 4, we conclude that the overall formulas for ag- $\mathrm{Nb}_{2} \mathrm{CT}_{\mathrm{x}}$ and ag$\mathrm{Nb}_{4} \mathrm{C}_{3} \mathrm{~T}_{\mathrm{x}}$ - in the presence of $\mathrm{Nb}_{2} \mathrm{O}_{5}$ that is excluded from the analysis - are $\mathrm{Nb}_{2} \mathrm{C}_{0.9} \mathrm{O}_{1.1}(\mathrm{OH})_{0.6} \mathrm{~F}_{0.3}$ and $\mathrm{Nb}_{4} \mathrm{C}_{2.3} \mathrm{O}_{0.9}(\mathrm{OH})_{0.7} \mathrm{~F}_{0.7}$. Comparing these two compounds, it is obvious that the number of oxygen 
terminations per surface $\mathrm{Nb}$ atom in the former is slightly higher than in the latter. Conversely, the concentration of F-terminations, per surface $\mathrm{Nb}$ atom, is roughly half in the former than in the latter. The OH-terminations are more or less comparable. Looking at the adsorbed water component (yellow regions in Fig. 4), it is slightly larger in the ag- $\mathrm{Nb}_{2} \mathrm{CT}_{\mathrm{x}}$ case, compared to ag- $\mathrm{Nb}_{4} \mathrm{C}_{3} \mathrm{~T}_{\mathrm{x}}$. These results are important because they confirm that what determines the terminations of a given MXene is not just the nature of the M-element, but also the number of those layers, viz. $n$ in $\mathrm{M}_{\mathrm{n}+1} \mathrm{X}_{\mathrm{n}} \mathrm{T}_{\mathrm{x}}$. These comments notwithstanding (and as noted above), why the average moles of terminations is $>2$ is unclear at this time, but could be due to the diffusion of some terminations within the C-vacancies.

Post-synthesis, the dominant surface group on most MXenes is $-\mathrm{F}$, viz. moiety III. This result is not surprising, given that HF is used for their production. However, another important result of this work is the instability of these F-terminations, as evidenced by the reduction in their concentrations after sputtering (Figure 5, and Table 5), and upon aging (Table 5, and compare bars labeled ap- and ag- $\mathrm{Ti}_{3} \mathrm{C}_{2} \mathrm{~T}_{\mathrm{x}}$ in Figure 4). The exchange of these $-\mathrm{F}$ groups for $-\mathrm{OH}$ as the samples age indicates that, in the presence of oxygen and/or water, the $-\mathrm{OH}$ termination is more favored, as predicted theoretically.[69]

Based on our results it should be possible to tailor the surface terminations to suit the properties sought. For example, in some energy storage applications, OH terminations may be desirable, in others, not.[69] The fact that it is possible to tune, or control, the surface terminations is thus an important advance. For example, it was found in recent work that the replacement of F-terminations with - $\mathrm{OH}$ groups led to an increase in the electrochemical performance of a $\mathrm{Ti}_{3} \mathrm{C}_{2} \mathrm{~T}_{\mathrm{x}}$-based supercapacitor.[70] The overall predisposition of Ti-MXenes to have $-\mathrm{OH}$ surface terminations is interesting, however, as it is the opposite of what is known for $\mathrm{TiC}$ and $\mathrm{TiO}_{2}$. $\mathrm{TiC}$ is known to react with water, dissociating the molecule into oxo groups.[71] Additionally, $\mathrm{TiO}_{2}$ typically only contains $\sim 25 \%-\mathrm{OH}$ groups, which is less than the $39-50 \%$ observed herein for $\mathrm{Ti}_{3} \mathrm{C}_{2} \mathrm{~T}_{\mathrm{x}}$ and $\mathrm{Ti}_{2} \mathrm{CT}_{\mathrm{x}} \cdot[43]$ 


\section{Conclusions}

Herein, we presented an in-depth analysis of the XPS spectra of the core levels of $\mathrm{Ti}_{3} \mathrm{C}_{2} \mathrm{~T}_{\mathrm{x}}, \mathrm{Ti}_{2} \mathrm{CT}_{\mathrm{x}}$, $\mathrm{Ti}_{3} \mathrm{CNT}_{\mathrm{x}}, \mathrm{Nb}_{2} \mathrm{CT}_{\mathrm{x}}$ and $\mathrm{Nb}_{4} \mathrm{C}_{3} \mathrm{~T}_{\mathrm{x}}$ cold pressed, 2D multilayered flakes. Before and after $\mathrm{Ar}^{+}$sputtering, the MXene surfaces are terminated by mixtures of $-\mathrm{O},-\mathrm{F}$, and $-\mathrm{OH}$, where a fraction of the latter are relatively strongly bonded to adsorbed $\mathrm{H}_{2} \mathrm{O}$ molecules. For freshly prepared samples, $-\mathrm{F}$ is the predominant surface group. With time, the latter is gradually oxidized, leading to the formation of metal oxyfluorides and a decrease in their concentration. The MXenes all oxidize over time, and demonstrate an increase in oxygen content. Additionally, some MXenes are more prone to oxidation than others, displaying a large percentage of oxidation products when allowed to age.

The ap- $\mathrm{Ti}_{3} \mathrm{C}_{2} \mathrm{~T}_{\mathrm{x}}$ compositions before and after sputtering were determined to be $\mathrm{Ti}_{3} \mathrm{C}_{2} \mathrm{O}_{0.3}(\mathrm{OH})_{0.32} \mathrm{~F}_{1.2}$ and $\mathrm{Ti}_{3} \mathrm{C}_{1.8} \mathrm{O}_{0.6}(\mathrm{OH})_{0.4} \mathrm{~F}_{0.8}$, respectively, indicating that sputtering selectively removes $\mathrm{C}$ from this MXene lattice, as well as reduces the concentration of F-terminations. The same holds true for ap- $\mathrm{Ti}_{3} \mathrm{CNT}_{\mathrm{x}}$ before and after sputtering, where their compositions were determined to be $\mathrm{Ti}_{3} \mathrm{CNO}_{0.23}\left(\mathrm{OH}-\mathrm{H}_{2} \mathrm{O}_{\mathrm{ads}}\right) \mathrm{O}_{0.3} \mathrm{~F}_{1.3}$ and $\mathrm{Ti}_{3} \mathrm{C}_{0.9} \mathrm{~N}_{0.9} \mathrm{O}_{0.5}(\mathrm{OH})_{0.03}\left(\mathrm{OH}-\mathrm{H}_{2} \mathrm{O}_{\mathrm{ads}}\right)_{0.3} \mathrm{~F}_{0.5}$, respectively. Combining these results with recent XANES measurements, we conclude that the average oxidation states of the Ti and $\mathrm{C}$ atoms in the $\mathrm{Ti}_{3} \mathrm{C}_{2} \mathrm{~T}_{\mathrm{x}}$ compositions are $\approx+2.4$ and $\approx-2.6$, respectively. It follows that the net charge on a MX block is positive and is neutralized by the adsorption of various negative terminations.

The ap- $\mathrm{Ti}_{2} \mathrm{CT}_{\mathrm{x}}$ compositions, before and after sputtering, however, were determined to be $\mathrm{Ti}_{2} \mathrm{C}_{0.9} \mathrm{O}_{0.3}(\mathrm{OH})_{0.1}\left(\mathrm{OH}-\mathrm{H}_{2} \mathrm{O}_{\text {ads }}\right)_{0.4} \mathrm{~F}_{0.8}$ and $\mathrm{Ti}_{2} \mathrm{C}_{0.9} \mathrm{O}_{0.5}(\mathrm{OH})_{0.1}\left(\mathrm{OH}-\mathrm{H}_{2} \mathrm{O}_{\mathrm{ads}}\right)_{0.2} \mathrm{~F}_{0.7}$, respectively. In this case, the major effect of sputtering is to convert some of the $\mathrm{OH}$ terminations to $\mathrm{O}$. The overall formulas for the other aged MXenes, measured after sputtering, were determined to be $\mathrm{Ti}_{3} \mathrm{C}_{1.8} \mathrm{O}_{0.6}(\mathrm{OH})_{0.9}(\mathrm{~F})_{0.3}$, $\mathrm{Ti}_{2} \mathrm{C}_{0.8} \mathrm{O}_{0.4}(\mathrm{OH})_{0.9}(\mathrm{~F})_{0.3}, \mathrm{Ti}_{3} \mathrm{C}_{0.6} \mathrm{~N}_{0.8} \mathrm{O}_{0.4}(\mathrm{OH})_{1.2}(\mathrm{~F})_{0.25}, \mathrm{Nb}_{2} \mathrm{C}_{0.9} \mathrm{O}_{1.1}(\mathrm{OH})_{0.6} \mathrm{~F}_{0.3}$ and $\mathrm{Nb}_{4} \mathrm{C}_{2.3} \mathrm{O}_{0.9}(\mathrm{OH})_{0.7} \mathrm{~F}_{0.7}$

Through this study, we were able to focus on the distribution of terminations for the various MXenes and the effect of changing several parameters such as the number of layers, M element and $\mathrm{X}$ element on the distribution of the terminations. In the case of Ti-MXenes, changing the number of layers, $n$, or the $\mathrm{X}$ 
element has little effect on the fraction of F-terminations. However, both of these factors affect the ratio of the $-\mathrm{O}$ to $-\mathrm{OH}$ terminations: increasing $n$ from 1 to 2 leads to an increase in the $-\mathrm{O}$ to $-\mathrm{OH}$ ratio, while changing $50 \%$ of the $\mathrm{X}$ element causes the $-\mathrm{O}$ to $-\mathrm{OH}$ ratio to decrease. For the Nb-MXenes, the mole $\%$ of F-terminations doubles from $\mathrm{Nb}_{4} \mathrm{C}_{3} \mathrm{~T}_{\mathrm{x}}$ to $\mathrm{Nb}_{2} \mathrm{CT}_{\mathrm{x}}$. The change in the $-\mathrm{O}$ to $-\mathrm{OH}$ ratio for the $\mathrm{Nb}-\mathrm{MXenes}$ shows the opposite trend of the Ti-MXenes, as $n$ increases, that ratio decreases.

When combined, these observations should impact the choice of the MXene to use for a specific application. The usefulness of quantifying under which conditions certain functional groups will be present on MXene surfaces is a significant development that will aid the intelligent design of any chemical systems that include these exciting and promising 2D compounds.

\section{Acknowledgments}

This work was supported by the European Research Council under the European Communities Seventh Framework Programme (FP7/2007-2013)/ERC Grant agreement no. [258509]. J. R. acknowledges funding from the Swedish Research Council (VR) grant no. 642-2013-8020 and from the KAW Fellowship program. The Swedish Foundation for Strategic Research (SSF) is acknowledged for support through the synergy grant FUNCASE and the Future Research Leaders 5 program. MN was partially sponsored by the Laboratory Directed Research and Development Program of Oak Ridge National Laboratory, managed by UT-Battelle, LLC, for the U. S. Department of Energy. We also acknowledge Dr. Jian Yang for providing $\mathrm{Nb}_{4} \mathrm{AlC}_{3}$ powders. 


\section{References}

[1] K.S. Novoselov, V.I. Fal'ko, L. Colombo, P.R. Gellert, M.G. Schwab, K. Kim, A roadmap for graphene, Nature, 490 (2012) 192-200.

[2] K.I. Bolotin, K.J. Sikes, Z. Jiang, M. Klima, G. Fudenberg, J. Hone, P. Kim, H.L. Stormer, Ultrahigh electron mobility in suspended graphene, Solid State Commun., 146 (2008) 351-355.

[3] R.R. Nair, P. Blake, A.N. Grigorenko, K.S. Novoselov, T.J. Booth, T. Stauber, N.M. Peres, A.K. Geim, Fine structure constant defines visual transparency of graphene, Science, 320 (2008) 1308.

[4] L. Ci, L. Song, C. Jin, D. Jariwala, D. Wu, Y. Li, A. Srivastava, Z.F. Wang, K. Storr, L. Balicas, F. Liu, P.M. Ajayan, Atomic layers of hybridized boron nitride and graphene domains, Nat. Mater., 9 (2010) 430-435.

[5] J.N. Coleman, M. Lotya, A. O'Neill, S.D. Bergin, P.J. King, U. Khan, K. Young, A. Gaucher, S. De, R.J. Smith, I.V. Shvets, S.K. Arora, G. Stanton, H.Y. Kim, K. Lee, G.T. Kim, G.S. Duesberg, T. Hallam, J.J. Boland, J.J. Wang, J.F. Donegan, J.C. Grunlan, G. Moriarty, A. Shmeliov, R.J. Nicholls, J.M. Perkins, E.M. Grieveson, K. Theuwissen, D.W. McComb, P.D. Nellist, V. Nicolosi, Two-dimensional nanosheets produced by liquid exfoliation of layered materials, Science, 331 (2011) 568-571.

[6] A.M. van der Zande, P.Y. Huang, D.A. Chenet, T.C. Berkelbach, Y. You, G.H. Lee, T.F. Heinz, D.R. Reichman, D.A. Muller, J.C. Hone, Grains and grain boundaries in highly crystalline monolayer molybdenum disulphide, Nat. Mater., 12 (2013) 554-561.

[7] S. Najmaei, Z. Liu, W. Zhou, X. Zou, G. Shi, S. Lei, B.I. Yakobson, J.C. Idrobo, P.M. Ajayan, J. Lou, Vapour phase growth and grain boundary structure of molybdenum disulphide atomic layers, Nat. Mater., 12 (2013) 754-759.

[8] R. Ma, T. Sasaki, Nanosheets of oxides and hydroxides: Ultimate 2D charge-bearing functional crystallites, Adv. Mater., 22 (2010) 5082-5104.

[9] V. Nicolosi, M. Chhowalla, M.G. Kanatzidis, M.S. Strano, J.N. Coleman, Liquid exfoliation of layered materials, Science, 340 (2013) 1420-+.

[10] S. Stankovich, D.A. Dikin, R.D. Piner, K.A. Kohlhaas, A. Kleinhammes, Y. Jia, Y. Wu, S.T. Nguyen, R.S. Ruoff, Synthesis of graphene-based nanosheets via chemical reduction of exfoliated graphite oxide, Carbon, 45 (2007) 1558-1565.

[11] M.K. Kinyanjui, C. Kramberger, T. Pichler, J.C. Meyer, P. Wachsmuth, G. Benner, U. Kaiser, Direct probe of linearly dispersing 2D interband plasmons in a free-standing graphene monolayer, EPL, 97 (2012) 57005.

[12] Y. Liu, R. Willis, K. Emtsev, T. Seyller, Plasmon dispersion and damping in electrically isolated two-dimensional charge sheets, Phys Rev B, 78 (2008) 201403.

[13] A. Politano, A.R. Marino, V. Formoso, D. Farias, R. Miranda, G. Chiarello, Evidence for acoustic-like plasmons on epitaxial graphene on Pt(111), Phys Rev B, 84 (2011) 033401.

[14] E. Bekyarova, M.E. Itkis, P. Ramesh, C. Berger, M. Sprinkle, W.A. de Heer, R.C. Haddon, Chemical modification of epitaxial graphene: spontaneous grafting of aryl groups, J. Am. Chem. Soc., 131 (2009) 1336-1337. 
[15] D.R. Dreyer, S. Park, C.W. Bielawski, R.S. Ruoff, The chemistry of graphene oxide, Chem. Soc. Rev., 39 (2010) 228-240.

[16] K.N. Kudin, B. Ozbas, H.C. Schniepp, R.K. Prud'homme, I.A. Aksay, R. Car, Raman spectra of graphite oxide and functionalized graphene sheets, Nano Lett., 8 (2008) 36-41.

[17] M. Naguib, M. Kurtoglu, V. Presser, J. Lu, J.J. Niu, M. Heon, L. Hultman, Y. Gogotsi, M.W. Barsoum, Two-dimensional nanocrystals produced by exfoliation of $\mathrm{Ti}_{3} \mathrm{AlC}_{2}$, Adv. Mater., 23 (2011) 4248-4253.

[18] M.W. Barsoum, MAX Phases: Properties of machinable ternary carbides and nitrides, John Wiley \& Sons 2013.

[19] M. Ghidiu, M.R. Lukatskaya, M.Q. Zhao, Y. Gogotsi, M.W. Barsoum, Conductive twodimensional titanium carbide 'clay' with high volumetric capacitance, Nature, 516 (2014) 78-81.

[20] M. Naguib, O. Mashtalir, J. Carle, V. Presser, J. Lu, L. Hultman, Y. Gogotsi, M.W. Barsoum, Two-dimensional transition metal carbides, ACS Nano, 6 (2012) 1322-1331.

[21] M. Naguib, J. Halim, J. Lu, K.M. Cook, L. Hultman, Y. Gogotsi, M.W. Barsoum, New twodimensional niobium and vanadium carbides as promising materials for Li-ion batteries, J. Am. Chem. Soc., 135 (2013) 15966-15969.

[22] J. Halim, M.R. Lukatskaya, K.M. Cook, J. Lu, C.R. Smith, L.A. Naslund, S.J. May, L. Hultman, Y. Gogotsi, P. Eklund, M.W. Barsoum, Transparent conductive two-dimensional titanium carbide epitaxial thin films, Chem. Mater., 26 (2014) 2374-2381.

[23] M. Naguib, V.N. Mochalin, M.W. Barsoum, Y. Gogotsi, 25th anniversary article: MXenes: a new family of two-dimensional materials, Adv. Mater., 26 (2014) 992-1005.

[24] M. Ghidiu, M. Naguib, C. Shi, O. Mashtalir, L.M. Pan, B. Zhang, J. Yang, Y. Gogotsi, S.J. Billinge, M.W. Barsoum, Synthesis and characterization of two-dimensional $\mathrm{Nb}_{4} \mathrm{C}_{3}$ (MXene), Chem Commun (Camb), 50 (2014) 9517-9520.

[25] B. Anasori, Y. Xie, M. Beidaghi, J. Lu, B.C. Hosler, L. Hultman, P.R. Kent, Y. Gogotsi, M.W. Barsoum, Two-dimensional, ordered, double transition metals carbides (MXenes), ACS Nano, (2015) DOI: 10.1021/acsnano.5b03591.

[26] M. Naguib, J. Come, B. Dyatkin, V. Presser, P.L. Taberna, P. Simon, M.W. Barsoum, Y. Gogotsi, MXene: a promising transition metal carbide anode for lithium-ion batteries, Electrochem. Commun., 16 (2012) 61-64.

[27] O. Mashtalir, M. Naguib, V.N. Mochalin, Y. Dall'Agnese, M. Heon, M.W. Barsoum, Y. Gogotsi, Intercalation and delamination of layered carbides and carbonitrides, Nature communications, 4 (2013) 1716.

[28] Q. Tang, Z. Zhou, P. Shen, Are MXenes promising anode materials for Li ion batteries? Computational studies on electronic properties and Li storage capability of $\mathrm{Ti}_{3} \mathrm{C}_{2}$ and $\mathrm{Ti}_{3} \mathrm{C}_{2} \mathrm{X}_{2}(\mathrm{X}$ = F, OH) monolayer, J. Am. Chem. Soc., 134 (2012) 16909-16916.

[29] J. Come, M. Naguib, P. Rozier, M.W. Barsoum, Y. Gogotsi, P.L. Taberna, M. Morcrette, P. Simon, A non-aqueous asymmetric cell with a $\mathrm{Ti}_{2} \mathrm{C}$-Based two-dimensional negative electrode, J. Electrochem. Soc., 159 (2012) A1368-A1373.

[30] M.R. Lukatskaya, O. Mashtalir, C.E. Ren, Y. Dall'Agnese, P. Rozier, P.L. Taberna, M. Naguib, P. Simon, M.W. Barsoum, Y. Gogotsi, Cation intercalation and high volumetric capacitance of two-dimensional titanium carbide, Science, 341 (2013) 1502-1505.

[31] O. Mashtalir, K.M. Cook, V.N. Mochalin, M. Crowe, M.W. Barsoum, Y. Gogotsi, Dye adsorption and decomposition on two-dimensional titanium carbide in aqueous media, Journal of Materials Chemistry A, 2 (2014) 14334-14338. 
[32] Q. Peng, J. Guo, Q. Zhang, J. Xiang, B. Liu, A. Zhou, R. Liu, Y. Tian, Unique lead adsorption behavior of activated hydroxyl group in two-dimensional titanium carbide, J. Am. Chem. Soc., 136 (2014) 4113-4116.

[33] X. Li, G. Fan, C. Zeng, Synthesis of ruthenium nanoparticles deposited on graphene-like transition metal carbide as an effective catalyst for the hydrolysis of sodium borohydride, International Journal of Hydrogen Energy, 39 (2014) 14927-14934.

[34] Z. Ling, C.E. Ren, M.-Q. Zhao, J. Yang, J.M. Giammarco, J. Qiu, M.W. Barsoum, Y. Gogotsi, Flexible and conductive MXene films and nanocomposites with high capacitance, Proceedings of the National Academy of Sciences, 111 (2014) 16676-16681.

[35] M. Naguib, R.R. Unocic, B.L. Armstrong, J. Nanda, Large-scale delamination of multilayers transition metal carbides and carbonitrides "MXenes", Dalton Trans., 44 (2015) 93539358.

[36] O. Mashtalir, M.R. Lukatskaya, M.Q. Zhao, M.W. Barsoum, Y. Gogotsi, Amine-assisted delamination of $\mathrm{Nb}_{2} \mathrm{C}$ MXene for Li-ion energy storage devices, Adv. Mater., 27 (2015) 35013506.

[37] S. Balendhran, S. Walia, H. Nili, S. Sriram, M. Bhaskaran, Elemental analogues of graphene: silicene, germanene, stanene, and phosphorene, Small, 11 (2015) 640-652.

[38] H.S. Liu, N.N. Han, J.J. Zhao, Atomistic insight into the oxidation of monolayer transition metal dichalcogenides: from structures to electronic properties, Rsc Advances, 5 (2015) 1757217581.

[39] M. Naguib, O. Mashtalir, M.R. Lukatskaya, B. Dyatkin, C. Zhang, V. Presser, Y. Gogotsi, M.W. Barsoum, One-step synthesis of nanocrystalline transition metal oxides on thin sheets of disordered graphitic carbon by oxidation of MXenes, Chem Commun (Camb), 50 (2014) 74207423.

[40] H. Ghassemi, W. Harlow, O. Mashtalir, M. Beidaghi, M.R. Lukatskaya, Y. Gogotsi, M.L. Taheri, In situ environmental transmission electron microscopy study of oxidation of twodimensional $\mathrm{Ti}_{3} \mathrm{C}_{2}$ and formation of carbon-supported $\mathrm{TiO}_{2}$, Journal of Materials Chemistry A, 2 (2014) 14339-14343.

[41] Z. Li, L. Wang, D. Sun, Y. Zhang, B. Liu, Q. Hu, A. Zhou, Synthesis and thermal stability of two-dimensional carbide MXene $\mathrm{Ti}_{3} \mathrm{C}_{2}$, Materials Science and Engineering: B, 191 (2015) 3340 .

[42] J. Li, Y. Du, C. Huo, S. Wang, C. Cui, Thermal stability of two-dimensional $\mathrm{Ti}_{2} \mathrm{C}$ nanosheets, Ceram. Int., 41 (2015) 2631-2635.

[43] S. Yamamoto, H. Bluhm, K. Andersson, G. Ketteler, H. Ogasawara, M. Salmeron, A. Nilsson, In situ x-ray photoelectron spectroscopy studies of water on metals and oxides at ambient conditions, J Phys-Condens Mat, 20 (2008) 184025.

[44] C. Mousty-Desbuquoit, J. Riga, J.J. Verbist, Electronic structure of titanium(III) and titanium(IV) halides studied by solid-phase X-ray photoelectron spectroscopy, Inorg. Chem., 26 (1987) 1212-1217.

[45] Y. Luo, P. Wang, L.P. Ma, H.M. Cheng, Hydrogen sorption kinetics of $\mathrm{MgH}_{2}$ catalyzed with $\mathrm{NbF}_{5}$, J. Alloys Compd., 453 (2008) 138-142.

[46] J. Halbritter, A. Darlinski, Angle resolved XPS studies of oxides at Nb-, NbN-, NbC- and $\mathrm{Nb}_{3} \mathrm{Sn}$ - surfaces, IEEE Trans. Magn., 23 (1987) 1381-1384. 
[47] M.T. Marques, A.M. Ferraria, J.B. Correia, A.M.B.d. Rego, R. Vilar, XRD, XPS and SEM characterisation of $\mathrm{Cu}-\mathrm{NbC}$ nanocomposite produced by mechanical alloying, Mater. Chem. Phys., 109 (2008) 174-180.

[48] V. Schier, H.J. Michel, J. Halbritter, ARXPS-Analysis of Sputtered TiC, SiC and $\mathrm{Ti}_{0.5} \mathrm{Si}_{0.5} \mathrm{C}$ Layers, Fresen J Anal Chem, 346 (1993) 227-232.

[49] E. Lewin, M. Gorgoi, F. Schäfers, S. Svensson, U. Jansson, Influence of sputter damage on the XPS analysis of metastable nanocomposite coatings, Surf. Coat. Technol., 204 (2009) 455462.

[50] S. Myhra, J.A.A. Crossley, M.W. Barsoum, Crystal-chemistry of the $\mathrm{Ti}_{3} \mathrm{AlC}_{2}$ and $\mathrm{Ti}_{4} \mathrm{AlN}_{3}$ layered carbide/nitride phases - characterization by XPS, J. Phys. Chem. Solids, 62 (2001) 811 817.

[51] M.R. Lukatskaya, J. Halim, B. Dyatkin, M. Naguib, Y.S. Buranova, M.W. Barsoum, Y. Gogotsi, Room-temperature carbide-derived carbon synthesis by electrochemical etching of MAX phases, Angew Chem Int Ed Engl, 53 (2014) 4877-4880.

[52] M. Naguib, J. Halim, J. Lu, K. Cook, L. Hultman, Y. Gogotsi, M.W. Barsoum, New twodimensional niobium and vanadium carbides as promising materials for Li-ion batteries, J. Am. Chem. Soc., 135 (2013) 15966-15969.

[53] G. Beamson, D. Briggs, High Resolution XPS of Organic Polymers: The Scienta ESCA300 Database, Wiley, 1992.

[54] T. Sultana, G.L. Georgiev, G. Auner, G. Newaz, H.J. Herfurth, R. Patwa, XPS analysis of laser transmission micro-joint between poly (vinylidene fluoride) and titanium, Appl. Surf. Sci., 255 (2008) 2569-2573.

[55] F. Santerre, M.A. El Khakani, M. Chaker, J.P. Dodelet, Properties of TiC thin films grown by pulsed laser deposition, Appl. Surf. Sci., 148 (1999) 24-33.

[56] U. Diebold, $\mathrm{TiO}_{2}$ by XPS, Surface Science Spectra, 4 (1996) 227.

[57] T. Tanuma, H. Okamoto, K. Ohnishi, S. Morikawa, T. Suzuki, Partially fluorinated metal oxide catalysts for a Friedel-Crafts-type reaction of dichlorofluoromethane with tetrafluoroethylene, Catal. Lett., 136 (2009) 77-82.

[58] P.M. Jayaweera, E.L. Quah, H. Idriss, Photoreaction of ethanol on $\mathrm{TiO}_{2}(110)$ single-crystal surface, J. Phys. Chem. C, 111 (2007) 1764-1769.

[59] K.H. Ernst, D. Grman, R. Hauert, E. Hollander, Fluorine-induced corrosion of aluminum microchip bond pads - an XPS and AES analysis, Surf. Interface Anal., 21 (1994) 691-696.

[60] I. Popova, V. Zhukov, J.T. Yates, Depth-dependent electrical impedance distribution in $\mathrm{Al}_{2} \mathrm{O}_{3}$ films on $\mathrm{Al}(111)$-detection of an inner barrier layer, Langmuir, 16 (2000) 10309-10314.

[61] A. Dacca, G. Gemme, L. Mattera, R. Parodi, XPS analysis of the surface composition of niobium for superconducting RF cavities, Appl. Surf. Sci., 126 (1998) 219-230.

[62] R. Romero, J.R. Ramos-Barrado, F. Martin, D. Leinen, $\mathrm{Nb}_{2} \mathrm{O}_{5}$ thin films obtained by chemical spray pyrolysis, Surf. Interface Anal., 36 (2004) 888-891.

[63] L. Chen, Q.Q. Sun, J.J. Gu, Y. Xu, S.J. Ding, D.W. Zhang, Bipolar resistive switching characteristics of atomic layer deposited $\mathrm{Nb}_{2} \mathrm{O}_{5}$ thin films for nonvolatile memory application, Current Applied Physics, 11 (2011) 849-852.

[64] S.Q. Guo, X. Zhang, Z. Zhou, G.D. Gao, L. Liu, Facile preparation of hierarchical $\mathrm{Nb}_{2} \mathrm{O}_{5}$ microspheres with photocatalytic activities and electrochemical properties, Journal of Materials Chemistry A, 2 (2014) 9236-9243. 
[65] C.F. Miller, G.W. Simmons, R.P. Wei, High temperature oxidation of $\mathrm{Nb}, \mathrm{NbC}$ and $\mathrm{Ni}_{3} \mathrm{Nb}$ and oxygen enhanced crack growth, Scr. Mater., 42 (2000) 227-232.

[66] Z. Weibin, W. Weidong, W. Xueming, C. Xinlu, Y. Dawei, S. Changle, P. Liping, W. Yuying, B. Li, The investigation of $\mathrm{NbO} 2$ and $\mathrm{Nb} 2 \mathrm{O} 5$ electronic structure by XPS, UPS and first principles methods, Surf. Interface Anal., 45 (2013) 1206-1210.

[67] Y. Xie, P. Kent, Hybrid density functional study of structural and electronic properties of functionalized $\mathrm{Ti}_{\mathrm{n}+1} \mathrm{X}_{\mathrm{n}}(\mathrm{X}=\mathrm{C}, \mathrm{N})$ monolayers, Phys Rev B, 87 (2013) 235441.

[68] S.-M.B. M. R. Lukatskaya, X. Yu, X.Q. Yang, M.W. Barsoum, Y.Gogotsi, Probing the mechanism of high capacitance in 2D titanium carbide using in situ X-ray absorption spectroscopy, Advanced Energy Materials, DOI: 10.1002/aenm.201500589 (2015).

[69] Y. Xie, M. Naguib, V.N. Mochalin, M.W. Barsoum, Y. Gogotsi, X. Yu, K.W. Nam, X.Q. Yang, A.I. Kolesnikov, P.R. Kent, Role of surface structure on Li-ion energy storage capacity of two-dimensional transition-metal carbides, J. Am. Chem. Soc., 136 (2014) 6385-6394.

[70] Y. Dall'Agnese, M.R. Lukatskaya, K.M. Cook, P.-L. Taberna, Y. Gogotsi, P. Simon, High capacitance of surface-modified 2D titanium carbide in acidic electrolyte, Electrochem. Commun., 48 (2014) 118-122.

[71] S.V. Didziulis, P. Frantz, S.S. Perry, O. El-bjeirami, S. Imaduddin, P.B. Merrill, Substratedependent reactivity of water on metal carbide surfaces, J. Phys. Chem. B, 103 (1999) 1112911140 . 


\section{Graphical Abstract}
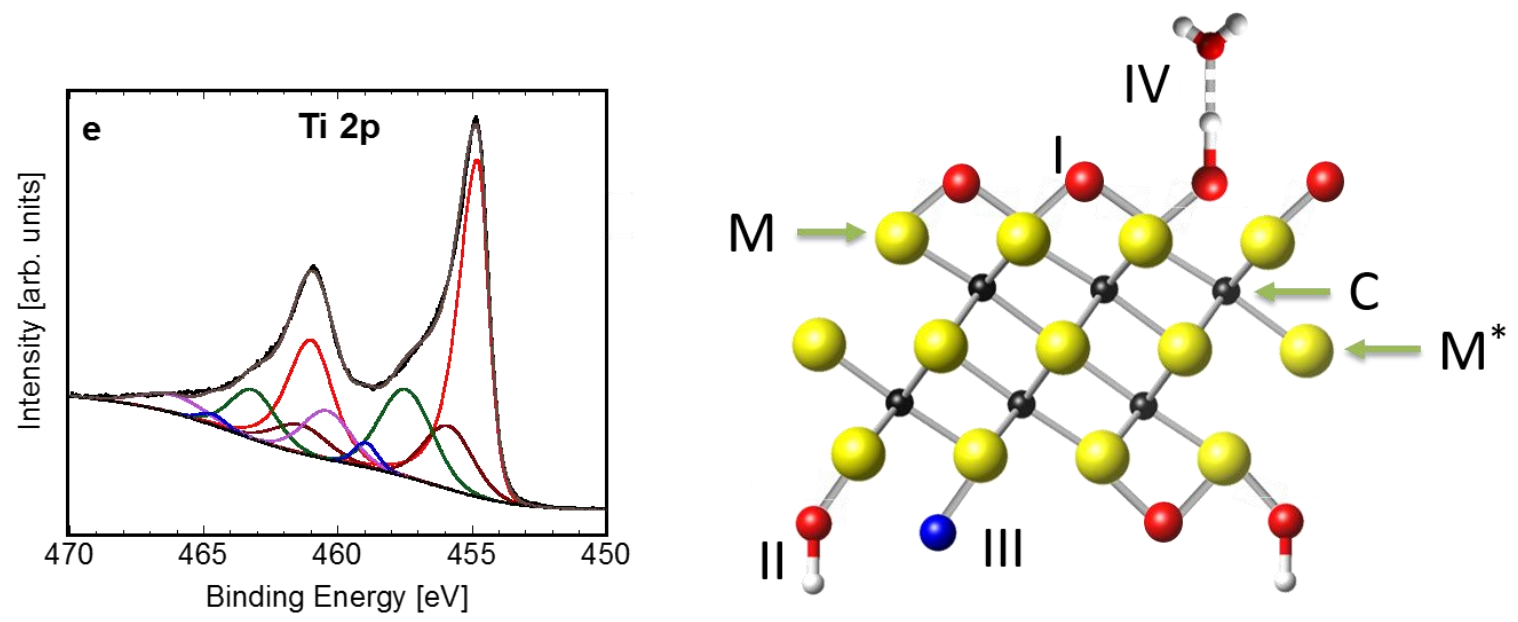